\title{
LA IMAGEN DE LA MONARQUÍA ESPAÑOLA
}

\section{THE IMAGE OF THE SPANISH MONARCHY}

\section{AUTOR:}

David Caldevilla Domínguez: Profesor del CAP 2 del Área de Comunicación Audiovisual y Publicidad en la Universidad Complutense de Madrid, la Universidad Europea de Madrid y Escuela Superior de Estudios de Relaciones Públicas (ESERP). david.caldevilla@ccinf.ucm.es

\section{CURRÍCULUM VITAE}

Diplomado en Magisterio por la Universidad de Zaragoza (España), licenciado en Comunicación Audiovisual por la Universidad Complutense de Madrid (España). Profesor en la Facultad de Ciencias de la Información de la Universidad Complutense. Secretario General del Fórum Internacional de Comunicación y Relaciones Públicas (España) y autor de varios artículos en revistas universitarias. Director de Operaciones de Imagométrica S.L. y ex directivo de varias firmas españolas del ámbito de la mercadotecnia.

\section{RESUMEN}

Hemos trazado, en este artículo, un recorrido por las labores constitucionales asignadas al Rey en España y su origen, lo que nos ha hecho analizar la historia de las monarquías europeas, en especial de la española, para analizar y comprender el marco actual de la Monarquía con todo lo que representa $y$, su relevancia en el contexto nacional e internacional. 
Pretendemos conocer cuál ha sido la evolución del papel de la Monarquía, con mayor interés en la persona del Monarca, y los poderes que ha ido adquiriendo o delegando a medida que transcurrieron las sucesivas épocas. Hemos recopilado e investigado los datos a través de diversas fuentes, que nos han proporcionado una visión general para lograr nuestros objetivos. Esto lo hemos conseguido gracias a consultas de bibliografía especializada, bufetes de abogados y visita a varias embajadas: Reino Unido, Holanda, Dinamarca, Bélgica, Noruega, Luxemburgo y Suecia, concretamente.

\section{PALABRAS CLAVE}

Monarquía española - Historia de la Monarquía - Rey Juan Carlos I - Monarquías europeas - Juan Carlos I.

\section{ABSTRACT}

In the present article we have looked into the constitutional tasks assigned to the King of Spain, as well as their origin, which has made us analyze the history of European monarchies, especially the Spanish one, in order to study and understand the current frame within which Monarchy operates, with every thing it represents, as well as its relevance in the national and international context. We aim at getting to know which has been the role of Monarchy, with especial emphasis on the figure of the Monarch, and the powers it has acquired or delegated to with the passing of the successive ages. We have gathered and researched data coming from a number of sources, which have provided us with a general view in order to achieve our objectives. This has been done thanks to research in especiallized bibliography, contacts with lawyers' offices and visits to several embassies: more specifically the United Kingdom, Holland, Denmark, Belgium, Norway, Luxembourg and Sweden. 


\section{KEY WORDS}

Spanish Monarchy - History of Monarchy - King Juan Carlos I - European Monarchies- Juan Carlos I.

\section{ÍNDICE}

1. Introducción: S. M. el Rey y su papel en la Constitución española

2. La Monarquía hispana

2.1 Marco histórico primigenio

2.1.1 Los Visigodos

2.1.2 Evolución del reino Visigodo: El reino de Tolosa (Francia)

2.1.3 Los visigodos en la Península

2.1.4 El reino de Toledo

$$
\text { 2.1.4.1 El ocaso del reino de Toledo }
$$

2.1.5 Organización política del Estado visigodo

2.2 La España musulmana: Al-Ándalus

2.2.1 El Emirato y el Califato Omeya

2.2.2 Reinos de Taifas y Dinastías Norteafricanas

2.2.3 La Dinastía Nazarí

2.2.3.1 Organización política del Estado

2.3 Los Reinos Cristianos (Desde el año 711 hasta el año 1100)

2.3.1 Marco histórico y organización política del Estado

2.3.1.1 Asturias

2.3.1.2 Navarra

2.3.1.3 Aragón y Condados catalanes

2.3.2 Evoluciones de los Reinos Hispanos 
2.4 Transición hasta nuestros días

2.4.1 Isabel II (1830-1904) Reina (1846-1868)

2.4.2 Alfonso XII (1857-1885)

2.4.3 Alfonso XIII (1886-1941)

2.4.4 D. Juan De Borbón y Battenberg (1913-1993)

2.4.5 Juan Carlos I (1938- ), Rey de España (1975- )

2.4.5.1 Marco histórico

2.4.5.2 Organización del Estado

3. Las Monarquías europeas

\author{
3.1 Bélgica \\ 3.2 Holanda \\ 3.3 Luxemburgo \\ 3.4 Noruega \\ 3.5 Dinamarca \\ 3.6 Suecia \\ 3.7 Comparativa de las Monarquías de los Países Nórdicos, Bélgica y \\ Holanda.
}

3.8 Gran Bretaña

3.8.1 Poderes constitucionales monárquicos

4. Conclusiones

5. Bibliografía

Para enmarcar el concepto de Monarquía hemos de retrotraernos históricamente al surgimiento de la primera Realeza española, propiamente dicha, y de la que el actual Monarca, S. M. Don Juan Carlos I. Comenzaremos por enumerar sus responsabilidades según la actual constitución vigente.

\title{
1. Introducción: S. M. el Rey y su papel en la Constitución española
}




\section{SOBRE EL REY DE ESPAÑA}

El día 22 de Noviembre de 1975 el entonces Príncipe Don Juan Carlos de Borbón, juraba lealtad a las Leyes Fundamentales ante las Cortes Españolas y el Consejo del Reino; era proclamado por el Presidente de las Cortes y del Consejo de Regencia como Rey de España.

Se cumplía así lo establecido en la Ley de Sucesión a la Jefatura del Estado de 1947.

Sin embargo, ese título de Rey no se lo confería sólo la Legalidad de entonces, sino también la propia tradición histórica. El día 14 de Mayo de 1977, Su Alteza Real el Conde de Barcelona renunciaba a sus derechos como heredero de su padre Alfonso XIII a favor de Don Juan Carlos. El cumplimiento de las Leyes y el respeto a una tradición centenaria coincidían en el Trono. Por esto, la Constitución declara de forma expresa que S.M. Don Juan Carlos de Borbón es el legítimo heredero de la dinastía histórica (Art. 57).

\section{LAS FUNCIONES DEL REY}

En su figura como Jefe de Estado, así le corresponde:

1. Sancionar y promulgar las Leyes.

2. Convocar las Cortes Generales, elecciones y referendos.

3. Proponer al candidato a Presidente de Gobierno, y en su caso, nombrarlo junto a su equipo de trabajo, así como poner fin a sus funciones en los términos previstos en la Constitución.

4. Expedir los Decretos acordados en el Conejo de Ministros, y presidir las sesiones de dicho Consejo cuando lo estime oportuno.

5. Conferir los empleos civiles y militares, siendo el mando supremo de las Fuerzas Armadas.

6. Conceder honores y distinciones con arreglo a las Leyes, 
7. El alto Pratonazgo de las Reales Academias.

8. Acreditar a los Embajadores y otros representantes diplomáticos de España.

9. Manifestar el consentimiento del Estado para obligarse de forma internacional, por medio de Tratados, a la conformidad con la Constitución y las Leyes.

10. Declarar la guerra y acordar la paz

Es la propia Constitución la que aclara el hecho de la determinación práctica del régimen bajo la decisión popular y bajo el beneplácito del Monarca de signo parlamentario. Don Juan Carlos I es un Monarca Constitucional: reina pero no gobierna. La misión concreta de los Reyes en estas Monarquías modernas es otra distinta y superior: representar a la Nación en su totalidad (lo que no corresponde a ningún partido político), convertirse en símbolos de Estado de unidad y permanencia. Ésta es la idea que anima a los sistemas constitucionales de Bélgica, Noruega, Suecia, Dinamarca, Holanda y Reino Unido, países todos ellos caracterizados por gozar de sociedades avanzada; de manera extraordinaria, con un alto nivel de vida, a conjugar la tradición de la Monarquía y la modernidad de la Democracia. Hay que mantener presente siempre en cualquier análisis la perspectiva de gracia por la cual el Rey Don Juan Carlos se constituye como Jefe de Estado, posición independiente a ideologías regentes, y de marcada necesidad demostrada en la adjudicación del resto de países representativos en la comunidad internacional. El Reyes, pues quien arbitra y modera el funcionamiento regular de las Instituciones, es decir, desempeña un poder que impide determinadas situaciones políticas de gravedad capaces de transformarse en auténticas conmociones nacionales. Asume la más alta representación del Estado español en las relaciones internacionales.

La Constitución española de 1978 establece en su artículo 1, apartado 3 que la "forma política del Estado español es la Monarquía parlamentaria".

El Título II de la constitución trata de "la Corona" en sus artículos 56 a 65:

\section{ARTÍCULO 56}


1. El Reyes el Jefe del Estado, símbolo de su unidad y permanencia, arbitra y modera el funcionamiento regular de las instituciones, asume la más alta representación del Estado español en las relaciones internacionales, especialmente con las naciones de su comunidad histórica, y ejerce las funciones que le atribuyen expresamente la Constitución y las leyes.

2. Su título es el de Rey de España y podrá utilizar los demás que correspondan a la Corona.

3. La persona del Reyes inviolable y no está sujeta a responsabilidad. Sus actos estarán siempre refrendados en la forma establecida en el artículo 64, careciendo de validez sin dicho refrendo, salvo en lo dispuesto en el artículo 65.2.

En este primer artículo referido a la figura del Rey se hace una primera aproximación a lo que van a ser sus funciones, su título y su forma de actuar, siempre de acuerdo con lo que dicta la Constitución y que se ampliarán y explicarán mejor en los siguientes artículos.

\section{ARTÍCULO 57}

1. La Corona de España es hereditaria en los sucesores de S. M. Don Juan Carlos I de Borbón, legítimo heredero de la dinastía histórica. La sucesión en el trono seguirá el orden regular de primogenitura y representación, siendo preferida siempre la línea anterior que las posteriores, en la misma línea el grado más próximo al más remoto, en el mismo grado el varón a la mujer, y en el mismo sexo, la persona de más edad a la de menos.

2. El Príncipe heredero, desde su nacimiento o desde que se produzca el hecho que origine el llamamiento, tendrá la dignidad de Príncipe de Asturias y los demás títulos vinculados tradicionalmente al sucesor de la Corona de España. 
3. Extinguidas todas las líneas llamadas en Derecho, las Cortes Generales proveerán a la sucesión en la Corona en la forma que más convenga a los intereses de España.

4. Aquellas personas que teniendo derecho a la sucesión en el trono contrajeran matrimonio contra la expresa prohibición del Rey y de las Cortes Generales, quedaran excluidas en la sucesión a la Corona por sí y sus descendientes.

5. Las abdicaciones y renuncias y cualquier duda de hecho o de derecho que ocurra en el orden de sucesión a la Corona se resolverán por una ley orgánica.

En este artículo se indica cual será el orden de sucesión a la Corona, cual puede ser el motivo de exclusión a ella y cómo se actuaría en caso de renuncia o abdicación.

\section{ARTÍCULO 58}

La Reina consorte o el consorte de la Reina no podrán asumir funciones constitucionales, salvo lo dispuesto para la Regencia.

En el artículo 58 se explica cual es la función de la Reina, en el caso de España, por ser ella la consorte del Rey, que se reduce a una función representativa y simbólica ya que carece de funciones constitucionales.

\section{ARTÍCULO 59}

1. Cuando el Rey fuere menor de edad, el padre o la madre del Rey y, en su defecto, el pariente mayor de edad más próximo a suceder en la Corona, según el orden establecido en la Constitución, entrará a ejercer inmediatamente la Regencia y la ejercerá durante el tiempo de la minoría de edad del Rey.

2. Si el Rey se inhabilitare para el ejercicio de la autoridad y la imposibilidad fuere reconocida por las Cortes Generales, entrará a ejercer inmediatamente la Regencia del Príncipe heredero de la Corona, si fuere mayor de edad. Si no 
fuere, se procederá de la manera prevista en el apartado anterior, hasta que el Príncipe heredero alcance la mayoría de edad.

3. Si no hubiere ninguna persona a quien corresponda la Regencia, ésta será nombrada por las Cortes Generales, y se compondrá de unas tres o cinco personas.

4. Para ejercer la Regencia es preciso ser español y mayor de edad.

5. La Regencia se ejercerá por mandato constitucional y siempre en nombre del Rey.

\section{"LA REGENCIA"}

En este artículo se recogen las situaciones y características que deben portar los futuros regentes de la Corona de España, cuyo trabajo siempre realizarán en nombre del Rey.

La Regencia se produce en los casos en que el Rey sea menor de edad o cuando éste se inhabilitare para el ejercicio de la autoridad con el consentimiento de las Cortes Generales.

\section{ARTÍCULO 60}

1. Será tutor del Rey menor la persona que en su testamento hubiese nombrado el Rey difunto, siempre que sea mayor de edad y español de nacimiento; si no lo hubiese nombrado, será tutor el padre o la madre, mientras permanezcan viudos. En su defecto, lo nombrarán las Cortes Genera les, pero no podrán acumularse los cargos de Regente y de tutor sino en el padre, madre o ascendentes directos del Rey.

2. El ejercicio de la tutela es también incompatible con el de todo cargo o representación política. 


\section{"TUTELA DEL REY"}

El tutor del Rey menor de edad será la persona nombrada por el Rey difunto, o en su defecto, el padre o la madre viudos, o la persona nombrada por las Cortes Generales. Este cargo no es compatible con otros puestos como la regencia o cualquier ocupación Política

\section{ARTÍCULO 61}

1. El Rey, al ser proclamado ante las Cortes Generales, prestará juramento de desempeñar fielmente sus funciones, guardar y hacer guardar la Constitución y las leyes y respetar los derechos de los ciudadanos y de las Comunidades Autónomas.

2. El Príncipe heredero, al alcanzar la mayoría de edad, y el Regente o Regentes al hacerse cargo de sus funciones, prestarán el mismo juramento, así como el de fidelidad al Rey.

\section{"JURAMENTOS"}

El Rey ha de ser proclamado ante las Cortes Generales y prestar juramento. Este mismo acto debe ser realizado por el Príncipe heredero y por el Regente.

\section{ARTÍCULO 62}

Corresponde al Rey:

1. Sancionar y promulgar las leyes.

2. Convocar a referéndum en los casos previstos en la Constitución.

3. Convocar y disolver las Cortes Generales y convocar elecciones en los términos previstos en la Constitución. 
4. Proponer el candidato a Presidente de Gobierno y, en su caso, nombrarlo, así como poner fin a sus funciones en los términos previstos en la Constitución.

5. Nombrar y separar a los miembros del Gobierno, a propuesta de su Presidente.

6. Expedir los decretos acordados en el Consejo de M [rostros, conferir los empleos civiles y militares y conceder honores y distinciones con arreglo a las leyes.

7. Ser informado de los asuntos de Estado y presidir, a estos efectos, las sesiones del Consejo de Ministros, cuando lo estime oportuno, a petición del Presidente del Gobierno.

8. El mando supremo de las Fuerzas Armadas.

9. Ejercer el derecho de gracia con arreglo a la ley, que no podrá autorizar indultos generales.

10. El Alto Patronazgo de las Reales Academias.

\section{ARTÍCULO 63}

1. El Rey acredita a los embajadores y otros representantes diplomáticos. Los representantes extranjeros en España están acreditados ante él.

2. Al Rey corresponde manifestar el consentimiento del Estado para obligarse internacionalmente por medio de tratados, de conformidad con la Constitución y las leyes.

3. Al Rey corresponde, previa autorización de las Cortes Generales, declarar la guerra y hacer la paz.

Las competencias del Jefe del Estado son extensas y muy importantes y se agrupan en tomo a tres poderes. En el artículo 62 las letras a) y b) hacen referencia al poder legislativo, las letras de la c) a la g) del mismo artículo junto con el artículo 63 
contienen las competencias con relación al poder ejecutivo; las letras de la h) a la j) las referidas al poder judicial.

\section{ARTÍCULO 64}

1. Los actos del Rey serán refrendados por el Presidente del Gobierno y, en su caso, por los Ministros competentes. La propuesta y el nombramiento del Presidente del Gobierno, y la disolución prevista en el artículo 99, serán refrendados por el Presidente del Congreso.

2. De los actos del Rey serán responsables las personas que los refrenden.

Para comprender el sentido de las competencias del Rey expuestas en los artículos 62 y 63 hay que tener en cuenta dos instituciones de origen medieval contenidas en este artículo: el principio de irresponsabilidad y la institución de refrendo. La primera supone que el Rey se hace irresponsable jurídicamente de todos los actos y de ellos depende el ministro o la persona que los refrenda. La segunda institución supone la traslación no sólo de la responsabilidad sino también de la decisión $\sim 1$ órgano que refrenda. De este modo, la totalidad de los actos del Rey se configuran como actos refrendados o actos obligados, sin margen alguno de discrecionalidad personal.

\section{ARTÍCULO 65}

1. El Rey recibe de los Presupuestos del Estado una cantidad global para el sostenimiento de su Familia y Casa, y distribuye libremente la misma.

2. El Rey nombra y releva libremente a los miembros civiles y militares de su Casa.

Este artículo se refiere a la total libertad del Rey en los asuntos referentes a la Casa Real. 


\section{La Monarquía hispana}

\subsection{Marco histórico primigenio}

\subsubsection{Los Visigodos}

Son el pueblo que, tras la presencia de Roma en Hispania (actuales España y Portugal) debido a su colapso, pueden ser considerados (pese a su origen foráneo -hoy serían en parte alemanes, polacos y ucranios-) los primeros españoles propiamente dichos.

Los visigodos se establecieron durante el s. II a. d. C en Escitia, cerca del mar Negro, al Oeste del Dniéper, mientras los ostrogodos se establecían al Este del mismo. En la primera mitad del S. IV fueron empujados hacia el Oeste y el Sur por los hunos hasta atravesar el Danubio y penetrar en el Imperio romano (376) al mando de Fritigermo, el cual derrotó al emperador Valente en la batalla de Adrianópolis (previamente habían adoptado el arrianismo por imposición de Valente). En 395 a las órdenes de Alarico, atravesaron y devastaron Macedonia y Tesalia, y tomaron Atenas, Corinto y Esparta. Saquearon Roma en el año 409, tras lo cual llegaron hasta Calabria con la idea de pasar a África, sin conseguirlo. Le sucedió Ataúlfo (410-415), que hizo que los visigodos se dirigieran a Provenza y luego hacia Aquitania conde uno de los tratados de "federación" los estableció con entrega de tierras y entraron al servicio de Roma para conquistar la península Ibérica, caída en manos de otros pueblos germánicos: los vándalos, suevos y alanos. De modo que, con aquel sistema de "alojamiento" (recibieron el derecho a establecerse en el territorio de las Galias de tal forma que no podían suponer ningún peligro para el Imperio), los grandes galos pudieron empezar a vivir corno lo habían hecho los grandes terratenientes romanos.

\subsubsection{Evolución del reino Visigodo: El reino de Tolosa (Francia)}

Los soberanos visigodos constituyeron entonces un reino del que Tolosa (actual Toulouse Francia-) fue la capital, que alcanzaría momentos de gran esplendor con Teodorico I (453- 
466) y Eurico (466-484), hijo de Teodorico I (419-451), éste último introdujo muchos elementos de la civilización romana y promulgó la " ley de los visigodos" ya que, hasta entonces, sólo disponían de costumbres orales para regirse. Bajo sus sucesor, Alarico II (484507), compilaron para la poblaciones romanas del reino un resumen de derecho romano, promulgado en 506 y éste "Código de Alarico" sería durante mucho tiempo el texto principal de derecho romano conocido en occidente.

El reino, sin embargo, estuvo constantemente acosado tanto por problemas internos como externos. La designación del monarca era electiva y la poderosa nobleza visigoda se mostró siempre reacia a los intentos de fundar una dinastía real de carácter hereditario. En el terreno internacional, tanto el Imperio bizantino como los francos que presionaban hacia el sur por el valle del Ródano, fueron la principal causa de que con Alarico II se iniciase la decadencia del reino de Tolosa (Clodoveo I derrotó a los visigodos en la batalla de Vovilli en 507).

\subsubsection{Los visigodos en la Península}

Excepto la Septimania (antigua Galia Narbonense), todas las antiguas posesiones de las Galias dejaron de pertenecer a los visigodos, quienes, por otra parte, conservaron sus posesiones en la península hispana.

Se produjeron dos fenómenos que de por sí demuestran que el período visigodo no fue en España nada más que una simple prolongación de la época romana. Por un lado, junto al puñado de dirigentes bárbaros que ocuparon las tierras hubo, sin duda, una inmigración de carácter popular, miles, probablemente, de germánicos medios, acompañados por sus familias y, a menudo, con sus propios esclavos se establecieron en distintas zonas, entre las que destaca "Tierra de Campos" (Castilla-León), conocida en la Edad Media, como "campos de godos". La población allí establecida era de humilde extracción, pobre, y fue fácilmente absorbida por las gentes autóctonas. Por otro lado, los godos no formaron sino una superestructura política por encima de la población del país ocupado (muy similar a la estructura antigua). Así que, en teoría, la población global del país quedó distribuida en dos categorías: los que mandaban políticamente, que eran los visigodos, y los que obedecían, que eran los hispanorromanos. En otras palabras, los marcos de la estructura social subsistieron tal como estaban establecidos. 
Pero hubo algo nuevo, y fue la valorización del trabajo como, fuente de riqueza. Representaba un contrato bilateral entre dos poseedores de mercancías (el valor tierra y el valor trabajo).

Si era posible alguna causa de conflicto, podía venir de la diferencia religiosa entre los godos arrianos y la gran masa católica, con la persecución le ésta última, así, la muerte del Rey Leovigildo (568-586), el futuro san Hermenegildo, sería por haberse éste convertido a la religión de los hispanorromanos. El príncipe Hermenegildo se rebeló, por razones políticas, contra su padre y se proclamó Rey y, además, se alió con los enemigos de su pueblo, los bizantinos y los suevos.

Si hubo represión por parte de los Reyes a manos contra los obispos o dignatarios de la Iglesia opuesta, fue normalmente por motivos políticos. Sin embargo, cuando en 587 el Rey Recaredo (586-601) se convirtió al catolicismo y con él la gran mayoría de la superestructura visigoda, los concilios de obispos reunidos en Toledo se convirtieron en un instrumento más de la política seguida por la Monarquía y del mismo modo, la Monarquía pasó a depender de un control teocrático.

Una de las principales preocupaciones de la Monarquía fue la de señalara sus funcionarios (militares, políticos o judiciales) la clase de principios que habrían de regirles al llevar a cabo sus funciones. El sistema legal visigodo se propuso ser suficiente de por sí para fomentar la justicia y la eficacia de los visigodos en a aplicación de sus leyes fue impresionante.

\subsubsection{El reino de Toledo}

Leovigildo fue el Rey arriano más importante de España. Con él se restauró el poder de la Monarquía y se inauguró hereditariamente el Reino de Toledo, al suceder a su hermano Liuva. El reino de iba a durar ciento cuarenta y tres años, con una serie de diecinueve Reyes, todos ellos subidos al trono por el método de la sucesión: Sisebuto (612); Suintila (621); Kintila (636) y Wamba (672) recibieron la corona por elección; Viterico (603); Gundemaro (160); Sisenando (631); Chindasvinto (642); Ervigio (680) y Roderico (170) a usurpación.

Finalmente, los nueve Reyes restantes subieron al poder por derecho hereditario: Leovigildo (568); Recaredo (601); Recaredo 11 (621); Ricimero (631); Tulga (669); Egika (687) y Vitiza (702). 
Aparte la revolución famosa de san Hermenegildo, la más grave con la que hubo de enfrentarse el reino visigodo, fue la del general Paulus que, bajo el reinado de Wamba (672680), se alzó con su ejército e hizo tambalearse la doctrina isidoriana del Estado hispano, con capital en Toledo. Aunque Wamba pudo dominar externamente la sublevación, el fomento del desacuerdo quedó patente el "morbo gótico" (se llama así a la afección goda por matar a sus Reyes). Propietario de inmensos bienes que suscitaban la ambición o la envidia, la Monarquía, era y sería incapaz de tener una base sólida. Las querellas sucesorias, que caracterizaban su accidentada historia, serían la causa de su hundimiento final.

\subsubsection{El ocaso del reino de Toledo}

Del mismo modo que había heredado la corona de su padre Vitiza procuró traspasar el trono a su hijo Akhila, pero a la muerte del Rey en 709, gran parte de la nobleza prefirió como Rey a Roderico (710), duque de la Bética, que había sido elegido Rey en Córdoba y ocupó pronto Toledo con el apoyo de la nobleza. Akhila (711) decide pedir ayuda a los musulmanes al mando del jefe beréber Tarik ibn Cibad. Roderico (D. Rodrigo) acudió a enfrentarse con las tropas invasoras siendo vencido en la batalla de Guadalete. La victoria decisiva de los musulmanes hizo que moralmente se viniera abajo el armazón del Estado visigodo. Tarik se dio cuenta de la oportunidad de hacerse con varias ciudades que, como Toledo, Córdoba y otras ocupó.

Además contaban con el apoyo de dos grandes grupos de partidarios incondicionales: a) Los siervos de los latifundios y los esclavos, b) Los judíos. Al comprobar el estado de desintegración de las estructuras visigodas, el jefe Tarik decidió quebrantar los acuerdos con los viticianos y en 712 se apoderaba de Sevilla, en 713 de Mérida y proclamó sobre las tierras peninsulares la soberanía del califa de Damasco.

Hoy se recuerda a los godos por haber sido los primeros en saquear Roma y, en consecuencia, por haber dado comienzo a la caída definitiva del antiguo orden mundial europeo.

\subsubsection{Organización política del Estado visigodo}


En el Estado Visigodo distinguimos el Reino y la Monarquía gobernante. El Reino lo formaban los hombres libres, herederos de la antigua soberanía popular, que de un protagonismo activo pasan a la condición pasiva de súbditos (pero no vasallos). La Monarquía es representada por el Rey, quien en principio aparece como caudillo militar, más tarde como jerarca político y, finalmente, como vicario divino con carácter cuasi-sacerdotal.

En las antiguas comunidades germánicas el Rey era elegido por la asamblea de los hombres libres; a este carácter abierto de elección la Monarquía visigoda opuso el predominio de una determinada estirpe que acaparó los nombramientos regios, así como las luchas por el poder y el fenómeno de la asociación al trono, mediante el cual un monarca determina quién ha de ser su sucesor.

Desde principios del siglo V hasta Amalarico (510-531) los monarcas fueron elegidos entre miembros de la estirpe de los Balthos. Durante toda su historia, salvo paréntesis pacíficos, los príncipes visigodos se vieron amenazados por atentados y destronamientos que llegaron a constituir un verdadero problema nacional. Además, la posibilidad de convertir la Monarquía electiva en hereditaria debió tentar ya a los primeros Reyes visigodos, bien fuera asegurando la elección cerrada dentro de la misma familia, bien por el sistema de eliminar a pretendientes indeseados, o por el procedimiento mencionado de asociar a alguien al trono.

En el siglo VII diversos preceptos de los Concilios de Toledo regularon las condiciones necesarias para la elección del Rey. El Concilio Venal año 636 ordenó que el candidato perteneciera a los nobles de sangre goda, un requisito reiterado un bienio después en el Concilio VI que agregó otros: no ser clérigo o monje tonsurado, no haber sufrido la pena infamante de decalvación y acreditar buenas costumbres; preceptos todos confirmados en el Concilio VII del año 653. Por otra parte, se decretó la inhabilitación para reinar de quien participara en conjuras destinadas a derribar la Monarquía, con el objetivo de corregir el hábito de los godos de deponer y asesinar a sus Reyes (morbo gótico).

En cuanto a los electores el tradicional uso germánico de que el monarca fuera elegido por la asamblea popular no tuvo vigencia en la realidad, con la excepción de Turismundo, aclamado por el pueblo al ruido de las armas durante las exequias de su padre Teodorico I tras la batalla de los Campos Cataláunicos.

En el periodo siguiente no debió existir un sistema electivo ni, por tanto, electores propiamente dichos, quedando la designación del Rey en manos de las clientelas más poderosas. El Concilio IV dispuso que el monarca fuera elegido por los principales del reino 
y los obispos, mientras el Concilio VIl precisó que intervinieran los personajes importantes de la Corte juntos a los prelados, reuniéndose donde hubiera muerto el Rey anterior.

Por otra parte al Rey se le exige el juramento de guardar la ley católica, proteger a la Iglesia, defender el reino y gobernarlo de manera justa, además de reprimir a los judíos o respetar la distinción entre el patrimonio personal del monarca y los bienes del fisco. A su vez, el pueblo debía jurarle fidelidad.

En lo referente al acto de coronación, se ha admitido el uso coyuntural de la corona entre los Reyes visigodos y parece probable que se realizara un acto solemne en tal situación.

La unción del príncipe tenía lugar con el acceso inmediato al trono, que le otorgaba un carácter cuasi-sacerdotal, a imagen de los Reyes del Antiguo Testamento.

El poder de la Monarquía visigoda se consideraba de origen divino, así lo acreditan numerosos textos legales y literarios de la época. La suprema dignidad regia fue protegida mediante una serie de prohibiciones, como la de consultar adivinos sobre la salud o posible muerte del príncipe, hablar mal de él en vida o incluso difamarla habiendo fallecido.

El poder ha de ser administrado para la consecución del bien común (salus populi). Para servir a este fin el Rey dirige la actividad política del reino, declarando la paz o la guerra, asume la potestad legislativa, es cabeza de la administración, juez supremo y máxima autoridad militar. Por otra parte debe atenerse a los límites marcados por las leyes mismas y sujetarse, además, por unas normas morales.

En la trama política, la reina debió desempeñar también un papel singular, tanto como orientadora ocasional de las directrices políticas de su marido, como a la hora de destronamientos que concluían con la muerte del monarca. En tales casos, la reina viuda no resultaría marginada de la confrontación entre la oligarquía vencedora y vencida. Algunas reinas viudas dispusieron de un notable poder fáctico que, para quienes contrajeran ulterior matrimonio con ellas, constituyó a buen seguro una auténtica oferta política. De ahí la significación pública de esas segundas nupcias en la pugna por el poder de la España visigoda.

\subsection{La España musulmana: Al-Ándalus}

Al-Andalus fue una civilización que irradió una personalidad propia tanto para Occidente como para Oriente. Situada en tierra de encuentros, de cruces culturales y fecundos 
mestizajes, al-Andalus fue olvidada, después de su esplendor, tanto por Europa como por el universo musulmán.

Tres son las etapas cruciales que se distinguen en sus ocho siglos de existencia en la Península Ibérica:

\subsubsection{El Emirato y el Califato Omeya}

Al-Ándalus, tierra de los vándalos, en árabe, es el término con el que se conoce la zona de ocupación musulmana en la Península Ibérica, que abarcó desde el siglo VIII hasta finales del XV y llegó a comprender gran parte del territorio español. La extensión del Estado islámico llamado al-Ándalus varió a medida que se modificaban las fronteras y, tanto hispanomusulmanes como castellano-aragoneses, avanzaban conquistando territorios.

La pujante civilización islámica de Oriente pronto se desbordará hacia Occidente: el Magreb, España, y hasta parte de Italia y Francia. Durante el siglo VIII, y a través del norte de África, penetraron en la península una serie de grupos y familias nobles árabes procedentes del este, y de grupos bereberes procedentes del Magreb, que paulatinamente se asentaron en tierras de al-Ándalus. Ello no significó una ruptura total con la cultura entonces imperante, la hispano-goda. Antes bien, ambas se entroncaron dando un resultado muy peculiar y autóctono, deslumbrante, que diferenció notablemente el Islam occidental del oriental.

La fusión entre árabe-bereberes e hispano-godos se produjo en un principio sin grandes traumatismos y con la naturalidad que sólo el tiempo y la cotidianeidad a veces procuran.

Durante la segunda mitad del siglo VIII se produjo una seria escisión en el imperio musulmán. Una ruptura dinástica que terminó con los Omeya que gobernaban en Damasco, para entronar a los Abasíes, que se asentaron en Bagdad. Un príncipe omeya huido de Damasco, Abderrahman I, penetraría en al-Ándalus formando un nuevo Estado con base en Córdoba: el emirato, independizándose de la política bagdadí.

Ocho emires se sucedieron del 756 al 929 en una época brillante culturalmente aunque oscurecida con diversos levantamientos muladíes y mozárabes- hasta que Abderrahman III decidió fundar un califato, declarándose emir al-Muminin (príncipe de los cReyentes) lo cual le otorgaba además del poder terrenal, el poder espiritual sobre la umma (comunidad de cReyentes). 
Este califa y su sucesor, al-Hakam II, supieron favorecer la integración étnico-cultural entre bereberes, árabes, hispanos y judíos. Ambos apaciguaron a la población, pactaron con los cristianos, construyeron y ampliaron numerosos edificios, algunos tan notables como la Mezquita de Córdoba- y se rodearon de la inteligencia de su época. Mantuvieron contactos comerciales con Bagdad, Francia, Túnez, Marruecos, Bizancio, Italia, y hasta Alemania.

\subsubsection{Reinos de Taifas y Dinastías Norteafricanas}

Sin embargo, no todos los sucesores de estos brillantes califas siguieron tan acertada política. Tras veintidós años de fitna (ruptura, o guerra civil) se abolió por fin el califato. Corría el año 1031.

Los hábitos secesionistas y rebeldes surgieron de nuevo con gran fuerza la división y la descomposición se impusieron en al-Ándalus. Todas las grandes familias árabes, bereberes y muladíes, quisieron hacerse con las riendas del país o, al menos, de su ciudad, surgiendo por todas partes Reyes de taifas, muluk al-Tawaif, que se erigieron en dueños y señores de las principales plazas. Este desmembramiento supuso el comienzo del fin para al- Ándalus, y ante esta debilidad, el enemigo cristiano se organizó como nunca antes lo hiciera para combatir a los musulmanes. La primera gran victoria sobre el Islam peninsular la protagonizó Alfonso VI cuando, en 1085, se hizo con la importante ciudad de Toledo.

La unidad étnico-religiosa lograda hasta el momento) también se resintió, surgiendo mercenarios, tanto musulmanes como cristianos (el Cid...), dispuestos a luchar contra sus propios correligionarios con tal de mantener determinadas situaciones de poder. Sin embargo, en esta época surgieron relevantes figuras en el campo del saber, y, en una constante emulación de los lujos orientales, se construyeron suntuosos palacios, almunias y mezquitas, y se celebraron las fiestas más comentadas, fastuosas y extravagantes de la Cuenca Mediterránea.

Mientras, a finales del siglo XI, en el Magreb occidental, hoy Marruecos, surgió un nuevo movimiento político y religioso en el seno de una tribu bereber del sur, los Lamtuna, que fundaron la dinastía almorávide. En poco tiempo, su actitud de austeridad y pureza religiosa convenció a gran parte de la desencantada población, y con su apoyo emprendieron una serie de contiendas logrando formar un imperio que abarcaría parte del norte de África y alÁndalus, que a través del Rey sevillano al-Mutamid, había pedido su ayuda para frenar el 
avance cristiano. Encabezados por Ibn Tashfin, penetraron los almorávides en la península, infligiendo una seria derrota a las tropas de Alfonso VI en Sagrajas. Pronto conseguirían acabar con los Reyes de taifas y gobernar al-Ándalus, no sin cierta oposición de la población, que se rebelaba contra su talante puritano y su rigidez. Algo que no le iba nada al hedonista y liberal pueblo andalusí. A pesar de todo, la nueva situación impuso un nuevo incremento del bienestar social y económico.

Los cristianos obtuvieron mientras tanto importantes avances, conquistando Alfonso I de Aragón, Zaragoza en 1118. Al mismo tiempo, los almorávides veían amenazada su propia supremacía por un nuevo movimiento religioso surgido en el Magreb: el almohade.

Esta nueva dinastía se generó en el seno de una tribu bereber procedente del corazón del Atlas que, encabezada por el guerrero Ibn Tumart, pronto se organizó para derrocar a sus predecesores, esgrimiendo parecidos argumentos de pureza revivificación religiosa. También desde Marrakech, gobernaron y se hicieron con las riendas de al-Andalus, dotándolo de cierta estabilidad y prosperidad económica y cultural. Fueron grandes constructores y también se rodearon de los mejores literatos y científicos de la época Sin embargo, al igual que los almorávides, terminaron por sucumbir ante la dejadez espiritual y el relajamiento de costumbres que casi siempre caracterizó a al-Andalus.

\subsubsection{La Dinastía Nazarí}

Cuando ya parecía todo perdido y el avance castellano era imparable, haciéndose Fernando m con una gran parte de las ciudades andalusíes en el siglo XIII, surgió en Jaén una nueva dinastía, la nasri (nazarí), fundada por aI-Ahmal' ibn Nasr, el célebre Abenamar del romancero, que habría de procurar un nuevo respiro a los musulmanes. Asentado en la ciudad de Granada, su reino abarcaba la región granadina, almeriense y malagueña, y parte de la jiennense y la murciana. Oprimido desde el norte por los reinos cristianos, y desde el sur por los sultanes meriníes de Marruecos, los nazaríes establecieron un reino basado en lo precario y la inestabilidad. A pesar de todo, Granada fue una gran metrópoli de su tiempo que acogía a musulmanes de todos los confines, y en la que se levantaron suntuosos palacios -la Alhambra-, mezquitas y baños públicos. En 1492 y, tras varios años de intrigas palaciegas y escaramuzas con los castellano-aragoneses que acechaban sus fronteras, el Rey Boabdil, Abu Abd Allah, capituló ante los Reyes Católicos, entregándoles Granada. Lo que sigue a 
continuación tiene todos los tintes de un drama pues, si bien las condiciones de capitulación eran generosas por parte de los vencedores, poco tardaron en ser ignoradas y comenzó una persecución y aculturación sin tregua de los moriscos que quedaron bajo dominio cristiano, hasta que tuvieron lugar las últimas expulsiones masivas de 1610.

\subsubsection{Organización política del Estado}

En este periodo histórico no se puede hablar de la Monarquía como estructura política, sino de emiratos y de califatos. En ambos casos se basaba en tres siguientes puntos:

- Poder absoluto del Emir o Califa. El emir tuvo siempre poder político y, desde el momento en que Abderramán III (929) tomó el título de califa también lo tuvo religioso. El poder político del emir o califa era un poder absolutista de base militar, ya que podía nombrar y deponer funcionarios, y era al mismo tiempo, juez supremo y general de los ejércitos. Como el poder dependía de su personalidad del monarca, a su muerte podían estallar verdaderas batallas de palacio y harén para imponer un sucesor que no siempre era el hijo mayor.

- La Administración. Estaba organizada y copiada de la estructura de tipo persa del imperio abbasí. La Corte de Córdoba (Palacio Medina Azabara) centralizó una administración en la que figuraban un 'primer ministro o hachib y grandes funcionarios de la Cancillería y el Tesoro. Al-Ándalus estaba dividido en 22 coras o provincias, gobernadas por un wali, que era comúnmente miembro de la nobleza árabe o local dominante. En las ciudades, los funcionarios se clasificaban según su función: el cuidado del mercado, el cuidado de la policía urbana, el cuidado de la justicia, los gobernadores de las provincias fronterizas (que contaban con tropas) adquirieron especial importancia en las épocas de lucha civiles o por el poder.

- Cobro de fuertes impuestos. Es lo que permitía mantener y sostener todo el aparato estatal. El Corán establecía dos tipos de impuestos: piara los musulmanes el diezmo o limosna, mientras que para la población cristiana se acumulaba un impuesto territorial o jarach, y un impuesto personal o chizya para judíos, muladíes y mozárabes. 
- Mantenimiento de un potente ejército. Este ejército estaba acampado principalmente en los alrededores de Córdoba y tenía fuertes destacamentos en las provincias de las fronteras. Éstas se dividían en Superior, Media e Inferior.

Con respecto a las leyes o códigos, los primeros documentos constitucionales del Islam son de procedencia griega, china e india, pero ninguno de ellos son una verdadera constitución en el sentido de una ley promulgada por un jefe de estado.

La historia del mundo no proporciona un solo caso de ley escrita de un Estado antes del tiempo del profeta del Islam (569/632), a pesar de que el estado existía en la sociedad humana cientos de años antes que él.

Muharnmad, nacido en la Meca en el 569, anunció a sus 40 años que había recibido la misión divina de predicar el Islam, por lo que convocó en una asamblea a todos los jefes de las tribus que habitaban en Medina; después de ciertas liberaciones ,se redactó un documento en donde quedaron impresos los derechos y los deberes del gobernante y de los gobernadores: el soberano podía ser elegido mediante contrato social por parte de la población, disponía de flexibilidad para la expansión y el desarrollo de su ciudad, se aprobaba la centralización de la administración de la justicia, la unidad del mando militar, (el jefe supremo, el Profeta, tenía derecho y prerrogativa de excluir a cualquier ciudadano participar en una campaña si sospechaba de su lealtad o temía la traición por su parte) presidía siempre la decisión del profeta en todas las disputas que estuviesen relacionadas con las surgidas entre la población. En resumen, el Profeta constituía la fuente de todas las leyes, con el Corán y la Sunnah como elementos de base, únicas fuentes del derecho en rigor.

\subsection{Los Reinos Cristianos (Desde el año 711 hasta el año 1100)}

Los Reinos Cristianos se consideraron desde su mismo comienzo como herederos del Reino Visigodo que salió derrotado ante los musulmanes, justificando la Reconquista no sólo como una Cruzada contra los 'moros infieles', y a favor de Jesús y su Iglesia Católica Apostólica y Romana, sino también como una vuelta a la legalidad.

\subsubsection{Marco histórico y organización política del Estado}


Entre los años 711 y 725, los musulmanes ocuparon casi toda la Península Ibérica, desapareciendo de este modo, el reino visigodo como tal. No obstante, en Asturias y en los Pirineos resistieron pequeños núcleos cristianos, con los que no existirá frontera hasta mediados de siglo. Tras unos años de sequías y malas cosechas (751-756), los musulmanes se retiraron al Sur. Ello favoreció la expansión de los núcleos cristianos que habían sobrevivido al Norte de la citada franja desértica.

\subsubsection{Asturias}

Se transformó en reino tras la batalla de Covadonga, probablemente en el año 720, cuando Pelayo se erigió Rey de su pueblo. Con Alfonso I (739-757) se repobló Asturias y se fortificaron los puntos de contacto con las avanzadas musulmanas (las cuales, no obstante, saquearon Asturias entre los años 794 y 795). En el ámbito asturiano existieron diferentes repoblaciones, durante los reinados de Alfonso II (791 -842), Ordoño I (850 -866) y Alfonso III (866 -910). Estas tierras repobladas pasaron a ser propiedad de los labriegos y los campesinos que se asentaron en ellas. La vida económica cotidiana se enmarcaba en las labores de la agricultura y del pastoreo, y éstas se desarrollaron en cada pueblo. En cuanto a los intercambios comerciales, eran inexistentes. La arquitectura asturiana experimentó un considerable auge y tuvo influencias bizantinas, árabes y carolingias.

\subsubsection{Navarra}

Este territorio se mantuvo independiente de musulmanes, de Asturianos y de francos, apoyándose alternativamente en unos y otros. En tiempos de Carlomagno (768-814) se ocuparan y anexionaron los territorios situados al Norte del Ebro: condados de Aragón, Sobrarbe, Ribagorza, Pallars y condados catalanes. Por su parte, el primer Rey de Navarra fue Íñigo Arista (820-851), cuyos sucesores mantuvieron la autonomía de este reino respecto de las Monarquías vecinas. Durante el siglo IX, Navarra conjugó su política con la asturleonesa. A mediados de esa centuria Navarra se unió a Aragón.

\subsubsection{Aragón y Condados catalanes}


Las repoblaciones comenzaron con la ocupación de Barcelona (año 801), y continuaron hasta llegar al río Llobregat en los últimos años del siglo. La economía de la zona estaba basada en la agricultura. Además, se iniciaron los intercambios comerciales. En relación con la arquitectura, cabe señalar la buena conservación de su patrimonio, así como sus influencias clásicas. Aragón, Sobrarbe, Ribagorza y Pallars se incorporaron a Navarra a lo largo de este siglo, mientras los condados de la Marca Hispánica dependían del de Barcelona, del que se independizaron posteriormente, ya en el siglo XI. Se favoreció una economía agraria y ganadera, así como los intercambios comerciales con los musulmanes. También hay que destacar el auge que experimentaron los mercados en diferentes localidades, que por estos años iniciaron las acuñaciones de monedas.

\subsubsection{Evoluciones de los Reinos Hispanos}

El Reino de León (que es el de Asturias, pero con el nombre cambiado debido a su nueva capital, que pasó de Oviedo a León, ya en la Meseta castellana) estaba formado en el siglo X por Portugal, Galicia, Asturias, León y Castilla.

En tiempos de Ordoño II (914-924), se produjo la ocupación temporal de León por Abderramán III en el año 920, fecha en la que también se conquistó La Rioja con ayuda de los navarros. Tras la batalla de Simancas (año 939), en la que el Rey Ramiro II derrotó a los musulmanes, se produjo la repoblación de Sepúlveda y de la cuenca del río Tormes. Los sucesores, Ordoño III (951-956) y Sancho I (956-966), fueron monarcas impuestos por la facción castellano-navarra, cuya influencia culminó con la subida al trono de Ramiro III (966984). En este reinado se registraron los ataques dirigidos por Almanzor que supusieron el retroceso de las avanzadillas de los ejércitos cristianos. Las actividades económicas siguieron siendo rudimentarias y no existió acuñación de moneda hasta el reinado de Vermudo II (984999). En este siglo se produjo un auge de la cultura mozárabe, y como ejemplos podemos citar la realización de la Biblia Hispalense y del Códice Virgiliano. También hay que resaltar las importantes obras en la arquitectura de estilo mozárabe.

La desintegración del Califato de Córdoba favoreció el renacimiento económico cristiano, gracias a las parias, que eran los tributos de los reinos taifas a cambio del respeto a sus fronteras por los reinos cristianos. De esta forma, el oro recibido de las parias era repartido por los Reyes cristianos entre los diferentes nobles f personalidades del alto clero, a los que 
sirvió para comprar las tierras entregadas a los labriegos y pastores en los siglos anteriores. Esta concentración de la propiedad condicionó el desarrollo económico y político a partir de la Baja Edad Media.

Políticamente, el Reino de León, el más fuerte de los iniciales en España, es adelantado medieval en el compartimento de poderes reales con el pueblo, constituyéndose en 1188 las primeras cortes medievales, en las que los burgueses (gentes de villas y ciudades) tenían representación, junto con el clero y la nobleza, ante el Rey.

\subsection{Transición hasta nuestros días}

Desde esos momentos iniciales de la Reconquista, a partir de sus Reinos protagonistas, la historia es bien conocida, con listados de Casas Reales tanto en Castilla-León y Aragón (por separado hasta 1469), como en Navarra (por separado hasta 1512) por la parte española (como único país desde 1512 hasta hoy), a las que unir la corona portuguesa desde 1139 hasta 1910 (se convierte en República) con una fase de unión a la Corona Española 1581-1668. Por ser épocas conocidas, pasamos ya al siglo XIX, que es el generador de la actual Monarquía tal y como la conocemos.

\subsubsection{Isabel II (1830-1904), Reina (1846-1868)}

Fue fruto del matrimonio de Fernando VII (último Rey absolutista de España) con su cuarta esposa, María Cristina de Borbón. Su nacimiento causó problemas dinásticos, pues el heredero había sido hasta ese momento el hermano de Fernando VII, Carlos María Isidro (hipotético Carlos V), que se negaba a aceptar el nombramiento de su sobrina Isabel como princesa de Asturias, y, por lo tanto, heredera al trono español.

Durante su minoría de edad fueron regentes su madre María Cristina que confió el gobierno a la rama liberal. Tuvo que enfrentarse al carlismo (primera Guerra Carlista, 1833-1839, surgida a raíz del conflicto sucesorio), y el general Badomero Espartero hasta 1843.

A los trece años fue declarada mayor de edad. A los 16 se la casó con su primo Francisco de Asís, con el cual tuvo nueve hijos, algunos de los cuales murieron al nacer.

En el periodo en el que ejerció de reina, se consolidó el tránsito en España de un Estado absolutista a otro liberal-burgués. Su reinado se inicia con la semi-concesión liberal de una 
carta otorgada, el Estatuto Real (1834). El definitivo impulso liberal se produjo en 1836 tras el golpe de Estado de La Granja.

El presidente de gobierno Juan Álvarez Mendizábal se encargó de la desamortización de bienes de la Iglesia, la creación de un Ejército capaz de dominar definitivamente al carlismo, la institucionalización del régimen y la elaboración de una nueva Constitución Progresista (1837).

Una revolución la obligó a renunciar a la Regencia y marcharse de España. Entre 1840 y 1843, Espartero, héroe de la guerra carlista, gobernó de forma autoritaria derivando en el regreso del Partido Moderado al poder. A partir de 1844, se estableció un liberalismo muy restrictivo con el general Narváez, caracterizado por el caciquismo. En 1845, el nuevo sistema promulgó la Constitución de 1845. Estalló la segunda Guerra carlista en Cataluña, que duró dos años (1846-1848).

Entre los años 1854 y 1856, el Partido Progresista volvió a gobernar por la fuerza (pronunciamiento de Vicálvaro de 1854). Destaca de este periodo la desamortización civil del ministro Pascual Madoz.

Narváez volvió a conseguir el poder durante un bienio más (1856-1858). La Unión Liberal sucedió al Partido Moderado entre 1858 y 1863, en tomo al militar Leopoldo O' Donnell. Éste fue un periodo de relativa estabilidad social. Se participó de forma activa en política exterior: guerra en Marruecos, intervención en México, en Indochina, en Annam, reincorporación a la Corona de Santo Domingo (actual República Dominicana) y presencia en el Pacífico (bombardeo de Callao -Perú- en 1866).

La crisis económica, las reiteradas sequías y las reivindicaciones de las rentas medias y del mundo obrero llevaron a la descomposición política de la última etapa del reinado de Isabel II (1864-1868). La respuesta del régimen fue el empleo de la fuerza rozando el sistema dictatorial con Luis González Bravo.

El 18 de septiembre de 1868 se inició la revolución con la sublevación de la escuadra. El general Serrano derrotó al general Pavía en el mente de Alcolea, y la reina se internó en Francia y fijó su residencia en París donde vivió hasta su muerte. En 1870, Isabel II abdicó en su hijo Alfonso XII.

\subsubsection{Alfonso XII (1857-1885)}


Alfonso XII nació en el Palacio Real de Madrid el 28 de noviembre de 1857. Sus padres eran la reina Isabel II y Francisco de Asís. Tras el triunfo de la Revolución de 1868, él y su familia se fueron al exilio a París. Esos años los aprovechó para completar su formación académica y militar.

En 1870, su madre abdicó en su favor. Las dificultades internas de la I República, la prolongación de la guerra con Cuba y el comienzo de la tercera Guerra carlista hicieron que aumentara el número de partidarios del restablecimiento de la Monarquía.

El golpe de estado incruento del general Pavía supuso el fin de la I República. En diciembre de 1874, el futuro monarca firmó el manifiesto de Sandhurst que expresaba su aprobación de la Monarquía parlamentaria. El 29 de diciembre, el general Martínez Campos precipitó la vuelta de Alfonso a España como Alfonso XII.

La restauración monárquica significaba el fortalecimiento de un sistema político bipartidista. El partido conservador, liderado por Cánovas del Castillo y apoyado por la aristocracia y las rentas medias moderadas compartía el poder político con el partido liberal, liderado por el riojano Práxedes Mateo Sagasta y apoyado por industriales y comerciantes. El turno de partido evitaba la toma del poder por la fuerza.

El monarca se casó en enero de 1878 con María de las Mercedes de Orleans, sobrina de Isabel II y nieta del Rey Luis Felipe de Francia. La reina murió seis meses después. Al año siguiente, Alfonso se volvió a casar con María Cristina de Habsburgo-Lorena, Archiduquesa de Austria con la que tuvo tres hijos.

El primer problema de su reinado fue la tercera Guerra Carlista. Tras sucesivos desastres carlistas, Alfonso XII fue reconocido como Rey legítimo por el militar carlista Ramón Cabrera el 11 de febrero de 1875. En política exterior, la paz de Zanjón (1878) simbolizaba el fin de la guerra de Cuba. Se daba paso a una etapa de estabilidad.

Durante su reinado se aprobó la Constitución de 1876, y se adoptaron medidas dirigidas a una centralización jurídico-administrativa. En política exterior, España se mantuvo neutral.

El 25 de noviembre de 1885, agonizaba Alfonso XII en el palacio madrileño de El Pardo. Su hijo, y heredero al trono, nació seis meses después de su muerte. El conservador Cánovas, preocupado por la estabilidad de la Monarquía y para evitar otro pleito dinástico, acordó con Sagasta el Pacto de El Pardo, cediendo el gobierno a los liberales.

\subsubsection{Alfonso XIII (1886-1941)}


Alfonso XIII nació el 17 de mayo de 1886 en el Palacio Real de Madrid. Es el hijo póstumo de Alfonso XII y María Cristina de Habsburgo-Lorena. Ejerció como Rey de España desde 1886 hasta 1931. Hijo póstumo de Alfonso XII y María Cristina de Habsburgo-Lorena reinó bajo la regencia de su madre hasta 1902, y de manera efectiva a partir de este momento. En 1906 contrajo matrimonio con Victoria Eugenia Juliana de Battenberg, con la que tuvo seis hijos. El inicio del reinado coincidió con un cambio generacional de los partidos dinásticos.

Cánovas, el dirigente del partido conservador, fue sustituido por Antonio Maura y en el Liberal Sagasta lo fue por José Canalejas.

Alfonso XIII tuvo que enfrentarse a problemas que procedían de gobiernos anteriores al mismo tiempo con otros inconvenientes como las guerras de Marruecos (culminadas con el desastre de Annual de 1921), el surgimiento de los nacionalismos vasco y catalán, el problema social, la quiebra del turnismo político (1918), el radicalismo de las organizaciones obreras y las fracturas en el sistema político.

Ante el debilitamiento del poder, se instauró al frente del gobierno el general Miguel Primo de Rivera (1923) tras el golpe de Estado que él protagonizó. La dictadura fue bien recibida por varios sectores de la sociedad en los primeros tiempos, pues consiguió terminar con la guerra de Marruecos (desembarco hispano-francés de Alhucemas en 1925) y desarrolló una intensa tarea de orden social y de incremento de las obras públicas.

Con el fracaso de Primo de Rivera en 1930, Alfonso XIII intentó restaurar el orden constitucional, pero los partidos tradicionales estaban en contra de la Monarquía. Las elecciones municipales del 13 de abril de 1931 dieron el triunfo en la mayoría de las ciudades a socialistas y republicanos. En medio de estas circunstancias el Rey optó por abandonar el país y así, evitar una lucha civil. El 14 de abril de 1931 se declaró la II República.

Alfonso XIII vivió en el exilio durante diez años. Sus últimos años los pasó en Roma, donde murió y fue enterrado en 1941. Sus restos fueron trasladados en 1980 al Panteón de los Reyes en el Monasterio de El Escorial (Madrid).

\subsubsection{Juan De Borbón y Battenberg (1913-1993)}

Nació en la Granja de San Ildefonso (Segovia) como tercer hijo del Rey Alfonso XIII. Contrajo matrimonio con María de las Mercedes de Borbón en 1935. 
Tras la renuncia de sus hermanos mayores Alfonso y Jaime a sus derechos dinásticos, se convirtió en príncipe heredero. Al morir su padre en 1941, asumió el título de conde de Barcelona. En 1946 marchó a Estoril (Portugal). Aunque inicialmente en la Guerra civil (19361939) trató de alistarse como voluntario en el ejército rebelde de Franco (y fue rechazado), su defensa de la Monarquía democrática le costó la entrada en territorio español.

Después de la muerte de Francisco Franco (1975), su hijo subió al trono como Juan Carlos I (22 de noviembre de 1975) dado que Franco prohibió expresamente que reinara sólo con el nombre de Juan, que es el empleado por él en su ámbito particular. En 1977, don Juan renunció a sus derechos sucesorios cediéndoselos a su hijo, por lo que dinásticamente hablando, don Juan Carlos era Rey legítimo de los españoles.

\subsubsection{Juan Carlos I (1938- ), Rey de España (1975- )}

Juan Carlos Víctor María de Borbón y Borbón, Juan Carlos I, nació en Roma el 5 de enero de 1938 -en pleno exilio de su abuelo y por ende, de toda la familia real española-. Es el segundo Hijo de Don Juan de Borbón y Battenberg y Doña María de las Mercedes de Borbón y Orleans.

Cuando nació Juan Carlos I, España estaba sumida de lleno en la guerra civil que culminaría con la victoria del general Francisco Franco Bahamonde y la instauración de una dictadura militar (1939-1975). Pasó su infancia en Suiza y Portugal. Llegó a España en 1948 tras un acuerdo entre su padre y el general Francisco Franco, para completar su educación. En 1962 contrajo matrimonio en Atenas con la princesa Sofía, hija del Rey Pablo de Grecia, con quien ha tenido tres hijos (Helena, Cristina y Felipe, futuro Felipe VI).

En julio de 1969 Franco designó a Juan Carlos I como sucesor a la Jefatura del Estado según los postulados de la Ley de Sucesión de 1947. Las Cortes ratificaron el nombramiento y lo proclamaron Príncipe de España. Desde entonces, y hasta la muerte de Franco, asumió interinamente las funciones del Jefe del Estado. Esto trajo consigo el enfrentamiento con su padre, pues los postulados de dicha ley no le reconocían sus derechos al trono como heredero de Alfonso XIII. El Conde de Barcelona acabó por aceptar la investidura de su hijo al ser el único medio de restituir la Monarquía en España. El 22 de noviembre de 1975 fue proclamado Rey de España por las Cortes. 
El 20 de noviembre de 1975 moría Francisco Franco. Tras ésta, Don Juan Carlos fue ascendido a Capitán General de los tres Ejércitos y dos días después, proclamado Rey ante las Cortes orgánicas y el Consejo del Reino.

Desde el inicio de su reinado reveló su conformidad para instaurar la democracia en España como medio de superar la división entre los españoles creada por la Guerra Civil y sus nefastas consecuencias. Para ello, mantuvo contactos con dirigentes de la oposición democrática, lo que le llevó a enfrentarse con el Presidente del Gobierno, Carlos Arias Navarro. El presidente del Gobierno fue sustituido en 1976 por Adolfo Suárez, encargado de la transición democrática.

En 1978 se aprobó una Constitución que delimitó sus poderes políticos. Desde entonces, sus funciones se centran en ejercer una labor de arbitraje entre los distintos poderes e instituciones del Estado y simboliza la más alta magistratura de la nación.

Su prestigio se vio incrementado tras el intento de golpe de Estado del 23 de febrero de 1981, ya que su actuación fue determinante para reprimir el triunfo de la rebelión militar.

La política exterior del reinado de Juan Carlos 1 se define por la recuperación del prestigio internacional de España con el ingreso en los Organismos multinacionales más representativos corno el Consejo de Europa en Estrasburgo (1977), la O.T.A.N. (1982) o el ingreso en la C.E.E. en 1986. España está entre los países más importantes del mundo en el marco de las relaciones internacionales.

\subsubsection{Marco histórico}

Los Borbones es una antigua casa feudal navarro-francesa que por emparentar con la casa real de los Capetos ha reinado en varias naciones. Se deriva su nombre del castillo de Bourbon, hoy Bourbon-l'Archambault, en el país Bourbonnais que en un antiguo señorío que se dice databa del s. VIII. La familia Borbón extendió sus ramas por España e Italia.

Al morir sin hijos Carlos II de España de la dinastía de Austria (Habsburgo), dejó por heredero a su sobrino Felipe V, nieto de Luis XIV de Francia (1700). El temor a que los Borbones extendieran su dominio sobre la herencia de los Habsburgo españoles, movió a Gran Bretaña, las Provincias Unidas y al Imperio a impugnar el testamento y declarar la llamada guerra de Sucesión española. La disputa concluyó con reconocimiento de Felipe V, a 
cambio de la renuncia de éste a sus derechos al trono de Francia y de la pérdida de los territorios de la Monarquía española italianos y flamencos.

\subsubsection{Organización del Estado}

Los Borbones españoles del siglo XVIII: Felipe V (1700-1724 y 1724-1746), Luis

I (1724), Fernando VI (1746-1759), Carlos III (1759-1788) y Carlos IV (1788-1808), desarrollaron una política reformista en todos los campos con el propósito de devolver a España un lugar destacado entre las potencias europeas.

Felipe V fue ayudado primero por consejeros franceses, relevados pronto por españoles pertenecientes a la primera generación de ilustrados. La política dinástica sostenida por Felipe V y su segunda esposa, Isabel de Farnesio, otorgó tronos en Italia a los hijos del matrimonio, dando origen a la rama Borbón-Sicilia.

Los reinados de Fernando VI y Carlos III significaron la plenitud del reformismo, al mismo tiempo que se evidenciaron los límites de la acción de gobierno. Uno de los principales focos de atención fue el desarrollo de la América española, cuyas posibilidades económicas aún estaban por explotar en su mayor parte.

El reinado de Carlos IV estuvo influenciado por las tensiones interiores y la evolución de los acontecimientos exteriores coincidiendo con el estallido revolucionario en Francia. El agotamiento de los hombres y los programas ilustrados reformistas y la implicación de España en los sucesos internacionales ocasionaron una honda crisis del Estado y de la dinastía. Tuvo su momento culminante en el enfrentamiento entre el Rey Carlos IV y su hijo, el príncipe de Asturias y futuro Fernando VII. La conjura de El Escorial (1807) y el motín de Aranjuez (1808), promovidos por el círculo de don Fernando contra el primer ministro Manuel Godoy, provocaron el destronamiento de Carlos IV y el nombramiento de Fernando VII. Los últimos años del siglo XVIII y los primeros del siglo XIX están marcados por el impacto de la Revolución Francesa y la época napoleónica. El descrédito de la familia real se acentuó con las abdicaciones de Bayona que suponían la concesión de los derechos a la Corona de España a Bonaparte, quien a su vez los transfirió a su hermano José (1808). La derrota de Napoleón provocó el regreso de los Borbones a Francia y a España en la persona de Fernando VII. 
Con Felipe V se había implantado en España la Ley Sálica, instaurada formalmente por Auto Acordado (1713). En una reunión de Cortes de 1789 fue derogada y se volvió al orden sucesorio tradicional de Castilla. Fernando VII, que sólo contaba con descendencia femenina, tuvo problemas al no ser publicada la ley.

En este periodo llega a Europa y al mundo occidental el liberalismo. En España ni Fernando VII ni su hija y sucesora Isabel II consiguieron entender el significado y alcance de dicha ideología, lo que derivó en el estallido revolucionario de 1868 y una nueva interrupción en la época borbónica que suponen el reinado don Amadeo I de Saboya (1870-1873) y la Primera República. Después de interrumpirse el ejercicio de la realeza por el destronamiento de Isabel II (1868), volvió a reanudarse con Alfonso XII (1874), hijo de Isabel II. Durante la Restauración borbónica, el Rey tuvo que enfrentarse al problema del movimiento obrero, el nacionalismo catalán y vasco y a una crisis ideológica iniciada a raíz de la derrota de 1898.

A la muerte de Alfonso XII le sucedió Alfonso XIII, quien reinó en 1923-1930 con la dictadura del general Primo de Rivera, destronado en 1931 por la Segunda República, último intento de modernización del país y de solución democrática.

En julio de 1936 las fuerzas más reaccionarias, comandadas por militares educados en las guerras de Marruecos, protagonizaron el Alzamiento fue da paso a la Guerra Civil española (1936-1939). Tras dicho enfrentamiento se inició la dictadura franquista (1939-1975) que concluyó con la muerte del Jefe de Estado. Por designación directa de Franco, se reinstauró la dinastía borbónica en 1975, cuando fue proclamado Rey e príncipe Juan Carlos, nieto de Alfonso XIII, con el nombre de Juan Carlos I, por expreso deseo suyo.

\section{Las Monarquías europeas}

\subsection{Bélgica}

En el marco del levantamiento belga iniciado en agosto de 1830, el 4 de octubre una coalición de católicos y liberales proclamó la independencia de Bélgica. En la Conferencia de Londres de 1831 las grandes potencias aceptaron la independencia de Bélgica a excepción de Holanda.

El 22 de noviembre de 1830, el Congreso Nacional decidió que la forma política de la futura Bélgica sería una Monarquía constitucional, parlamentaria y hereditaria. 
La Constitución belga estipulaba un poder legislativo bicameral elegido por propietarios varones y con un Rey cuyos actos ejecutivos tenían que ser refrendados por un ministro responsable. Leopoldo I fue el fundador de la dinastía belga. Ha sido calificado como un modelo de monarca constitucional.

Los holandeses reconocieron la independencia de Bélgica en 1839 y se firmó un tratado de paz entre ambos. Así, se acordaba que la mitad de Luxemburgo pasaría a ser provincia belga, correspondiendo a los holandeses el control nominal del resto del Gran Ducado, además de Limburgo. Las potencias europeas confirmaron a Bélgica como "Estado independiente y perpetuamente neutral".

El declive económico tras la separación de los mercados de Holanda fue contrarrestado por el primer programa de una nación europea en la construcción del ferrocarril en 1840.

Durante los últimos años de Leopoldo I en el trono belga se tomaron medidas de importancia decisiva: en 1860 se abolieron los arbitrios aduaneros que impedían la libre circulación de mercancías, el 8 de diciembre de ese mismo año se creó el Crédit Communal, y el 16 de marzo de 1865 se fundó la Caja General de Ahorros de Jubilación.

Leopoldo I fue sucedido por su hijo. El reinado de Leopoldo II se caracterizó por una evolución en diversos aspectos de la vida pública. El monarca se enfrentó a numerosos problemas interiores. Los liberales y católicos lucharon por el control de la educación. Se acordó que los gobernantes locales decidieran si se subvencionaban o no las escuelas parroquiales.

La industrialización de los años 80 y el aumento de la población habían producido unas condiciones inhumanas de vida en las ciudades, por lo que los distintos gobiernos establecieron una legislación para mejorar las viviendas y las características del trabajo.

Como los trabajadores no contaban con el derecho al voto, empezaron a organizarse con el fin de obtener los mismos derechos. La huelga general de 1893 forzó al Parlamento a instituir el sufragio universal entre los hombres adultos, modificado para quedar limitado a graduados universitarios, mayores de 50 años y propietarios.

Otra dificultad interior fue la carencia de un idioma común. La mayoría eran flamencos que hablaban holandés. El idioma de las clases dirigentes era el francés, el que hablaban los valones. En Brabante se hablaban ambas lenguas. La expansión del sufragio supuso un trato igualitario para ambas lenguas en los asuntos oficiales. 
A comienzos de su reinado, Leopoldo II financió una expedición al río Congo, y en la Conferencia de Berlín de 1885 se le reconoció como soberano del Estado Libre del Congo. En 1908 se transfirió el control total de esta empresa al Estado.

Por iniciativa del Rey, se pusieron en marcha obras públicas de gran envergadura para desarrollar la infraestructura económica del país. Para convertir a Bruselas en una gran capital, el Rey mandó ejecutar numerosas obras urbanísticas. Leopoldo II tuvo por sucesor al trono a su sobrino Alberto.

Aunque el tratado de 19 de abril de 1939 había hecho de Bélgica un reino independiente y neutral, esto no fue impedimento para ser invadida por los alemanes en las dos guerras mundiales.

El 4 de agosto de 1914, las tropas alemanas cruzaron la frontera de Bélgica. Alberto permaneció al lado de sus tropas durante toda la guerra en la Bélgica no ocupada. Los alemanes confiscaron propiedades y deportaron civiles belgas. Durante la guerra murieron más de 80.000 soldados y civiles belgas.

La gran ofensiva aliada desplegada a partir del 28 de septiembre de 1918 liberó la costa de Bélgica y llevó a los alemanesa acordar un armisticio y a retirarse. Por el Tratado de Versalles, Alemania cedió Eupen, Malmédy y Moresnet a Bélgica, incorporando al reino $989,3 \mathrm{~km}^{2}$ y 64.500 habitantes.

Alberto I apoyó la expansión industrial y el desarrollo de una fuerte flota mercante como el mejor método para la recuperación nacional.

Hacia 1927 empezó un periodo de prosperidad económica debida, en parte, a un plan de saneamiento financiero del gobierno. En 1928 se creo el Fondo Nacional de Investigación Científica.

La introducción del voto para los hombres no cualificados supuso el aumento del número de votantes socialistas.

Bélgica abandonó la neutralidad y en 1920 firmó una alianza militar con Francia. En 1925 firmó los acuerdos de Locarno, en los que Gran Bretaña, Francia, Alemania e Italia confirmaron la inviolabilidad territorial de Bélgica. En 1936, Bélgica volvió a la neutralidad.

El 11 de mayo de 1940, las tropas alemanas volvieron a invadir Bélgica. El ejército y las tropas francesas y británicas que vinieron en ayuda de Bélgica fueron rápidamente superados por las fuerzas invasoras. El Rey Leopoldo III se rindió incondicionalmente junto al resto de sus fuerzas el 28 de mayo y fue hecho prisionero. El 30 de mayo los ministros, con 
el apoyo del Parlamento, acordaron despojar a Leopoldo III de los poderes y derechos a gobernar. De acuerdo con la Constitución, las Cámaras legislativas debían recurrir a la regencia si el Rey se encontraba en la situación de imposibilidad de reinar. El 20 de septiembre el Príncipe Carlos, hermano de Leopoldo III, fue elegido Regente.

Durante la Regencia, se restableció la actividad económica a causa del saneamiento financiero en octubre de 1944, la recuperación de la industria del carbón, y, más tarde, la ayuda del Plan Marshall. Un hito político importante fue la introducción del derecho a voto para las mujeres en las elecciones legislativas (ley de 19 de febrero de 1948). La cuestión relativa al Rey Leopoldo se resolvió prolongando en el verano de 1945 indefinidamente la Regencia del príncipe Carlos.

En el campo internacional, cabe mencionar la fundación de la Unión Económica entre Bélgica, Holanda y Luxemburgo en 1944, la adhesión de Bélgica a la Organización de las Naciones Unidas (ONU) en 1945, a la Organización del Tratado del Atlántico Norte (OTAN) en 1948, y al Consejo de Europa en 1949.

El 1 de agosto de 1950, el Rey solicitó a las Cámaras y al gobierno que confiaran sus prerrogativas reales a su hijo, el Príncipe Balduino que, el 11 de agosto, recibió el título de "Príncipe Real". Leopoldo abdicó el 16 de julio de 1951 cuando su hijo ya cumplió la mayoría de edad. El 17 de julio de 1951, el Rey Balduino prestaba el juramento constitucional ante las Cámaras reunidas.

En el plano internacional, Bélgica había firmado, el 8 de abril de 1951, el tratado que instituía la Comunidad Europea del Carbón y el Acero. Con el tiempo, esta institución será el origen de la Comunidad Económica Europea, actualmente Unión Europea. Bélgica, Francia, Alemania Occidental, Luxemburgo, Italia y Holanda constituyeron la Comunidad Europea del Carbón y del Acero (CECA) en 1952. Bruselas se convirtió en la sede de la comisión de gobierno y de la mayoría de su burocracia. E se año el país se convirtió en miembro de la Comunidad Europea de Energía Atómica (EUFATOM).

Este período se caracterizó por una serie de problemas internos: la cuestión escolar, la independencia del Congo, las huelgas de 1960-1961 y la disputa entre flamencos y valones. En 1960, se acordó oficialmente la independencia del Congo y se esbozaron las grandes líneas de una constitución. En 1962, los administradores belgas de la ONU llevaron a cabo la independencia de Ruanda y Burundi.

La permanente rivalidad entre flamencos y valones acabó con frecuencia en 
alborotos durante la década de 1960. En enero de 1968 las disputas entre valones y flamencos llevaron al hundimiento del gobierno.

El líder socialcristiano Gaston Eyskens formó una coalición con los socialistas en junio que se mantuvo hasta noviembre de 1972. Le sucedió en el poder una coalición de tres partidos bajo liderazgo socialista que se acabó fragmentando en enero 1974. Tras las elecciones de marzo, el líder socialcristiano, Léo Tindemm formó una coalición con los liberales y la agrupación valona hasta febrero de 1977. Los resultados de las elecciones celebradas en abril impidieron la formación de un nuevo gobierno hasta lograr un acuerdo que otorgara una mayor autonomía regional.

En la década de 1980, los socialcristianos formaron los gabinetes ministeriales. En enero de 1989, se aprobó un programa para transferir el poder desde el gobierno central a las tres regiones etnolingüísticas.

En noviembre de 1991, los socialcristianos consiguieron una mayoría reducida.

Martens dimitió como máximo dirigente del partido y su sucesor, Jean-Luc Dehaene, formó un nuevo gobierno de centro-izquierda en marzo de 1992. Finalmente, en mayo de 1993, Bélgica se convirtió oficialmente en un Estado federal compuesto por tres regiones.

El Rey Balduino murió el 31 de julio de 1993 sin descendencia, por lo que la corona recayó en su hermano, Alberto II.

Durante la segunda mitad de 1993, el monarca promulgó la nueva Constitución. Ese mismo año, por primera vez, una pareja real belga asistió a las ceremonias en las que se celebraban las diferentes fiestas comunitarias y regionales.

El gobierno que entró en funciones en junio de 1995, una coalición de democristianos y socialistas, concedió prioridad a llevar el déficit presupuestario a los límites impuestos por el Tratado de Maastricht para lograr la adhesión a la Unión Monetaria Europea, y una reforma del sistema de la seguridad social.

El príncipe Felipe nació el 15 de abril de 1960. Es el primogénito del Rey Alberto II y de la reina Paola, y es, por lo tanto, el primero en la línea de sucesión al trono.

En agosto de 1993, se le designó Presidente de honor de la Oficina Belga de Comercio Exterior. En octubre de 1993, fue nombrado Presidente del Consejo Nacional de Desarrollo Duradero. Además de estos papeles, el príncipe mantiene contactos con representantes de instituciones, o incluso estudiantes para estar informado de todos los aspectos de la sociedad belga. 


\subsection{Holanda}

La Casa Real Holandesa es la Casa de Orange-Nassau. El vínculo entre esta dinastía y el territorio que se conoce ahora por Holanda data ya de casi seis siglos. En el curso de los años, los Orange fueron comandantes, altos cargos, caudillos políticos y finalmente Reyes constitucionales. El actual jefe de estado, la Reina Beatriz, desde 1980, cumple su misión en la democracia parlamentaria holandesa de una forma que infunde mucho respeto entre los holandeses, según las encuestas de popularidad.

El nombre de Nassau se debe al castillo de Nassau, construido a comienzos del Siglo XII en un territorio que pertenece al estado alemán de Hesse. Los lazos entre los Países Bajos y los Nassau se remontan al año 1403, cuando el conde Engelbert I de Nassau contrajo matrimonio con Johanna de Polanen. A partir de ese momento, esta rama de los Nassau perteneció a las más importantes familias holandesas de la nobleza. En aquella época no existía un Estado holandés independiente. La mayor parte de las provincias, que más tarde constituirían los Países Bajos, estaban gobernadas por la dinastía borgoña .El conde Engelbert de Nassau y sus herederos conquistaron posiciones influyentes en la corte borgoña.

Uno de los descendientes de Engelbert de Nassau, René de Chalon, poseía también el principado independiente de Orange, situado al sur de Francia. El título de "Príncipe de Orange", vinculado a estas posesiones, era hereditario. Al morir Chalon en 1544, la herencia pasó a su primo Guillermo de Nassau, quien se daría a conocer como Guillermo de Orange. Por su caudillaje en la lucha por la independencia contra el Rey de España, Guillermo de Orange es considerado como uno de los fundadores del estado holandés. Adquirió el título honorífico de Padre de la Patria. El nombre y el color "orange" (anaranjado) se convirtieron con el correr del tiempo en un símbolo de los Países Bajos. El territorio y la ciudad de Orange fueron a parar, a fines del Siglo XVII, a domino francés, pero el título de Príncipe de Orange permaneció unido a los Nassau holandeses. En el Siglo XVIII, Orange-Nassau e convirtió en el nombre de toda la dinastía. Desde 1815, cuando los Países Bajos se transformaron en un reino, el hijo mayor del jefe de estado lleva el título de Príncipe de Orange. Actualmente, este título lo ostenta el actual heredero al trono, Su Alteza Real el Príncipe Willem-Alexander.

En Holanda se hace distinción entre los conceptos de Familia Real y Casa Real. No todos los miembros de la Familia son siempre miembros de la Casa. La Familia Real está compuesta 
por la Princesa Juliana, el Príncipe Bernhard y todos sus hijos, nietos y sus respectivos cónyuges. La calidad de miembro de la Casa Real está regulada por ley. Son miembros el jefe de estado, el jefe de estado retirado y los miembros de la Familia Real que entran en consideración para la sucesión al trono.

El derecho a la sucesión al trono lo poseen todos lo miembros de la Casa de Orange-Nassau que son familia del monarca reinante hasta el tercer grado. Al asumir un nuevo Rey sus funciones, algunos miembros de la Casa Real pueden perder el derecho a la sucesión y, por tanto, también la calidad de miembro de la Casa Real. Éste es igualmente el caso si un miembro de la Casa Real contrae matrimonio sin que la representación popular haya dado su consentimiento a tal efecto por ley. Según la ley sobre la Calidad de Miembro de la Casa Real de 1985, la calidad de un miembro concluye también si éste pierde la nacionalidad holandesa o si a un miembro se le concede exención por Decreto Real.

La Casa Real está compuesta actualmente por la Reina Beatriz y el Principe Claus, sus tres hijos, el jefe de estado anterior, la Princesa Juliana, su esposo el Príncipe Bernhard, la hermana menor de la Reina, la Princesa Margarita, su esposo el Excmo. Sr. D.Pieter van Vollenhoveny, sus cuatro hijos y su nuera.

La Constitución estipula que la corona de un monarca Reinante pasa por sucesión.

Para la sucesión de la Reina Beatriz entran primero en consideración sus tres hijos, después su hermana la Princesa Margarita y luego los cuatro hijos de ésta.

La Constitución no dice nada sobre la creencia religiosa del Rey. Todos los Reyes o reinas que han reinado pertenecieron a la iglesia protestante holandesa.

En Holanda, el nuevo jefe de estado no es coronado, sino investido. El monarca no tiene que esperar tampoco hasta que sea investido Rey (o Reina) para ejercer sus funciones.

Durante la investidura se exhiben las regalías, símbolos de poder y de dignidad real (la corona, el cetro, el globo imperial, la espada y el pendón reales).Además se coloca sobre la mesa un ejemplar de la constitución holandesa encuadernada en pergamino.

El Rey forma junto con los ministros el gobierno. El Rey, como jefe de estado, autoriza las leyes y el ministro confiere su responsabilidad constitucional.

La Reina Beatriz se entrevista con frecuencia con el presidente del gobierno y cada lunes lo recibe en palacio. También habla regularmente con los demás ministros, con el vicepresidente del Consejo de Estado, con los parlamentarios, comisarios en las provincias y alcaldes. 
La Reina desempeña un papel importante en la formación de gobiernos. Cuando se celebran elecciones parlamentarias, la Reina es quien después de haber sido aconsejada, nombra informador o informadores que reciben el encargo de formar un nuevo gobierno a base del resultado de las elecciones. Después de que los partidos políticos han llegado a un acuerdo sobre el programa para un nuevo gobierno, la Reina nombra y toma juramento a los nuevos ministros del estado. Todos los años, la Reina desempeña el papel principal en la apertura oficial del año parlamentario, que tiene lugar el tercer martes de septiembre.

La Reina mediante la asistencia y a atención a los acontecimientos importantes que acontecen en Holanda, queda capacitada para dar contenido a los tres derechos del monarca en una democracia moderna: el derecho de consultar, el derecho de advertir y el derecho de estimular.

\subsection{Luxemburgo}

Las fuerzas europeas se encuentran en el Congreso de Viena entre 1814 y 1815 para reorganizar Europa tras Napoleón. Fue aquí donde se decidió crear un Reino de Holanda, convirtiendo a Guillermo de Orange-Nassau en soberano. El ducado de Luxemburgo le fue concedido a Guillermo I, elevado a la categoría de Gran Ducado. En teoría, el Congreso de Viena definió Luxemburgo como un estado independiente, pero Guillermo I lo unió a su reino. De esta forma, Luxemburgo se convierte en el siglo XIX en provincia de Holanda.

Luxemburgo consiguió la verdadera independencia con el Tratado de Londres de 1839. Este Tratado, en efecto, confirmaba que el Gran Ducado era independiente, mientras que, a la vez, estaba siendo unido al Reino de Holanda, entrando a formar parte de la Confederación Alemana. Poco después se separa, con el territorio de habla francesa, concedido al Reino de Bélgica y la zona de habla alemana, entrando a formar parte del Gran Ducado Independiente.

La identidad nacional del territorio se fue formando a medida que se iba adquiriendo más independencia e iba siendo reformado por la presencia del Gobierno de la Casa del Gran Ducado, desde 1890.

El pacto de familia de la Casa Nassau establece que la Corona del Gran Ducado tiene que dar paso a los Nassau-Weilbourg, una vez que muere el último descendiente masculino de la línea Orange-Nassau. Así, cuando Guillermo II muere sin descendencia, la Corona pasa a 
manos del Duque Adolfo de Nassau, mientras la hija mayor de Guillermo III, Guillermina, sucede al trono de su padre en Holanda. La unión personal entre Luxemburgo y Holanda acabó con la muerte de Guillermo III.

El Gran Duque Adolfo de Nassau se convierte en el fundador de la dinastía nacional de Luxemburgo el 9 de Diciembre de 1890 a la edad de 73 años. Desde entonces, sus descendientes directos le han sucedido en el trono. Adolfo de Nassau se convirtió en el propietario de las ruinas del Castillo Vianden, y los Castillos de Berg y Fischbach. Dejó todas las decisiones políticas en manos del presidente del gobierno de Luxemburgo: Paul Eyschen. Su hijo mayor, Guillermo IV, fue nombrado Teniente-Representante en 1902 y sucedió a su padre en 1905, quien a causa de problemas de salud, delegó el poder a su mujer María-Ana de Braganza, con quien tuvo siete hijas, por lo que la sucesión fue de carácter problemático a su muerte. El 16 de Abril de 1907, la Cámara de los Diputados aprobó que fuera la hija mayor de Guillermo IV la sucesora al trono: la princesa María-Adelaida el 25 de Febrero de 1912.

La Gran Duquesa María-Adelaida prestó juramento el 18 de Junio de 1912. Dos años después el 12 de Agosto de 1914, las tropas alemanas invadieron el Gran Ducado.

La Duquesa siempre afirmó su interés por las cuestiones políticas y sociales.

Fuertemente influenciada por su educación católica y convencida de que era soberana por la gracia de Dios, reclamó el derecho a intervenir en los asuntos políticos. Sin embargo, no siendo muy apreciada por la izquierda, ésta pidió su dimisión. Dimisión que fue aceptada porque el Primer Ministro Emile Reuter le convenció de que lo mejor ere abdicar a favor de su hermana menor Carlota.

La Gran Duquesa Carlota accedió al trono, en momentos muy difíciles, el 15 de

Enero de 1919, afirmando su deseo de permanecer sobre la política. Su posición fue reforzada por los resultados de un referéndum político efectuado el 28 de Septiembre de 1919. Su matrimonio con el Príncipe Félix de Borbón-Parma contribuyó a anclar el Gran Ducado.

La revisión de la Constitución en 1919 redefinió las prerrogativas de la Corona, declarando a la nación como soberana y limitada por la fuerza del soberano.

El período de entreguerras está marcado por la entrada de Luxemburgo en la Liga de las Naciones el 16 de Diciembre de 1920, por la creación de la Unión Económica con Bélgica, la BLEU, en 1921. 
No obstante, en la grave crisis del 29, acentuada en toda Europa, Luxemburgo optó por enfrentarse a ella, saliendo adelante.

Las tropas alemanas invadieron Luxemburgo el 10 de Mayo de 1940, violando su neutralidad. La Gran Duquesa hubo de exiliarse con su familia y el Gobierno. Fue en Londres donde se asentó, con los Aliados y la Oficina Principal de Luxemburgo. Desde allí animó a su país a la resistencia, y su actitud fue fortalecida por el espíritu de unidad de la gente. Tanto es así, que una multitud entusiasta, reclamó su retorno el 14 de Abril de 1945.

Más tarde, en el 1964, abdicó a favor de su hijo, el Gran Duque Juan de Nassau.

Tras la invasión germana del 10 de mayo de 1940, el Gran Duque consorte ha de refugiarse en otros países, y entretanto, se forma como teniente y, después como capitán. El 10 de Septiembre de 1944, atraviesa Luxemburgo con las tropas americanas, liberando el Gran Ducado y prosigue sus campañas con los Aliados en Alemania, a pesar del final de las hostilidades. En 1945 regresa a Luxemburgo, y en 1953 contrae matrimonio con su Alteza la Princesa Josefina-Carlota de Bélgica, con quien tiene cinco hijos.

El Gran Duque fue un miembro del Consejo del Estado desde 1951 hasta 1961, lo que le capacitó para convertir en familiar la maquinaria de la vida legislativa y política del país.

El 24 de Diciembre de 1999 el Gran Duque anuncia su abdicación a favor de su hijo el Gran Duque Enrique, el 7 de Octubre de 2000, quien se casa con la Princesa de Bélgica JosefinaCarlota. Desde entonces ella ha asistido a su marido en sus deberes. Además, se ha mostrado interesada por problemas de salud de los niños; ella es la presidenta de la Cruz Roja de Luxemburgo desde 1964.

Luxemburgo es una democracia de carácter representativo, en la forma de una Monarquía constitucional. El primer artículo de la Constitución declara que el Gran Ducado es "libre, independiente y un Estado democrático indivisible". El artículo 51 indica que está regulado por un sistema de democracia parlamentaria. La nación es la fuente del poder del soberano.

La fuerza del soberano reside en la nación pero el ejercicio de la fuerza del soberano es confiado al Gran Duque. Éste sólo tiene aquellos poderes que la Constitución y las leyes le confieren.

De acuerdo al artículo 33 de la Constitución, el Gran Duque es la cabeza del Estado, símbolo de su unidad y garantía de la independencia nacional. Él posee el poder ejecutivo, conforme a lo acordado por la Constitución. Representa al Estado en sus relaciones exteriores. 
Desempeña un papel esencial en el ejercicio del poder legislativo, y la justicia se administra en su nombre. De todas formas, él no puede interferir en el ejercicio de la fuerza judicial.

La función de su persona es claramente representativa, goza de inviolabilidad de su persona y de libertad desde la responsabilidad de tomar decisiones provisionales de acuerdo a los derechos patrimoniales y la lista civil. Es de destacar que su carácter representativo está basado en el principio de delegación hereditaria de la Corona como establece la Constitución.

El Gran Duque puede promulgar leyes, hacer las regulaciones y los decretos necesarios para reforzar las leyes, pero nunca suspender las leyes. Además, está capacitado para organizar y supervisar los servicios administrativos y nombrar cargos civiles y militares, y ordenara las fuerzas armadas para mantener el orden y la seguridad en el país.

En teoría, el Gran Duque decide la organización de su gobierno, que forma con al menos tres miembros, mientras que elige libremente sus ministros y destituyendo a quien considere oportuno.

En la práctica, el Gran Duque elige un mediador o "armateur" que, generalmente se convierte en Primer Ministro, quien realmente se encarga de elegir el equipo de miembros del Gobierno -generalmente figuras sobresalientes de los grupos políticos representados en la Cámara de los Diputados. El Gran Duque puede destituir a un ministro, pero hasta ahora no ha hecho uso de ese poder.

Por último, también tiene el poder de firmar tratados con otros estados, pero debe conseguir el asentimiento de la Cámara de los Diputados.

Los poderes del Gran Duque están recogidos en los Artículos 33 al 48 de la Constitución.

\subsection{Noruega}

En lo que hoy es Noruega, alrededor del año 800 d. C. se construyeron barcos de guerra que fueron enviados en expediciones de pillaje que iniciaron la era vikinga. Los vikingos eran comerciantes, colonizadores y exploradores y también saqueadores. Alrededor del año $875 \mathrm{~d}$. C., establecieron asentamientos en Irlanda, Gran Bretaña, Islandia y en las islas arcadas, Feroe y Shetland. Un siglo después, alrededor del 985 d. C. Erik el Rojo dirigió a los vikingos a Groenlandia desde Islandia; algunos años después, su hijo, Leif Ericson, fue quizá el primer europeo que arribó, sin saberlo, a América del Norte. Grupos de vikingos procedentes del 
norte penetraron en Rusia, pero su influencia en la formación del Estado ruso es todavía un tema de debate e investigación. Otros se asentaron en Francia, dónde fundarían la futura Normandía.

En el siglo IX el Rey Harald 1, de Vestfold (sureste de Noruega), realizó con éxito el primer intento de formar un reino noruego unido poco antes del año 900, pero cuando murió, alrededor del 933, sus hijos dividieron Noruega y provocaron disensiones y guerras entre los herederos de Harald que interrumpieron la unidad y muchos de los príncipes locales se negaron a renunciar a su independencia. Además de estas luchas interiores los Reyes daneses y suecos intentaban anexionar a sus dominios el territorio noruego.

Introducción del cristianismo. En el 995 Olaf 1, un bisnieto de Harald I, se convirtió en Rey. Antes de llegar al trono, Olaf había vivido en Inglaterra, donde se había convertido al cristianismo, por lo que intentó imponer esta religión en Noruega y tuvo un éxito parcial.

Cinco años después de su ascensión al trono entró en conflicto con el Rey Sven I de Dinamarca y murió en una batalla. Noruega se vio dividida por un corto periodo de tiempo, pero fue reunificada por Olaf II el Santo, que llegó al trono en el 1015. Continuó con la labor religiosa de su antecesor, utilizó la fuerza contra todos aquellos que se negaban a ser bautizados, y hacia el 1025 era más poderoso de lo que lo había sido ningún Rey noruego hasta entonces, aunque provocó la enemistad de poderosos nobles, quienes, junto al Rey de Inglaterra y Dinamarca Canuto I el Grande, enviaron a Olaf al exilio a Rusia en 1028.

Regresó dos años después y murió en una batalla, Posteriormente fue canonizado como santo patrón de Noruega.

Reyes nativos. Al morir Canuto en 1035, los partidarios de su padre llamaron desde Rusia al hijo de Olaf, Magnus I el Bueno; se convirtió en Rey y unió Dinamarca y Noruega en una sola corona. Durante los tres siglos siguientes, Noruega fue gobernada por una sucesión de Reyes nativos. Aunque hubo interrupciones intermitentes en el país a causa de guerras entre aspirantes rivales al trono, Noruega comenzó a emerger como una nación unida que gozaba de una cierta prosperidad fundamentada en su gran flota comercial. Los noruegos se habían convertido en cristianos devotos y la poderosa Iglesia era uno de los poderes más fuertes del reino. En 1046 Magnus convirtió a su tío Harold en cogobernante. Al morir Magnus un año después, éste se convirtió en Rey con el nombre de Harold III el Despiadado; murió cuando tomaba parte en la invasión de Inglaterra en 1066. El último Rey de la dinastía fundada por Harold III fue Sigurd I, quien reinó desde 1103 hasta 1130. 
A la muerte de Sigurd tuvieron lugar conflictos dinásticos. De los muchos Reyes posteriores, el más importante fue Sverre, Rey desde 1184 hasta 1202. Hombre de Estado muy hábil, Sverre construyó una Monarquía fuerte y debilitó bastante el poder religioso y nobiliario. Durante el reinado de Haakon IV el Viejo, desde 1217 hasta 1263, Noruega alcanzó el apogeo de su prosperidad en la edad media y de su poder político y cultural. En 1262 se añadió al reino Islandia, y Haakón y su hijo, Magnus VI el Legislador, incrementaron la autoridad real. La muerte en 1319 de Haakón V sin herederos varones dio el trono al Rey sueco Magnus VII Eriksson, un niño de tres años, nieto de Haakón. En 1343 a Magnus le sucedió su hijo, Haakon VI, y en 1380, Olaf II, Rey de Dinamarca e hijo de Haakón, se convirtió en Rey de Noruega con el nombre de Olaf IV. El joven Rey ejerció un mandato sólo de forma nominal, pues el poder real estaba en manos de su madre, Margarita I, que a la muerte de su hijo le sucedió como gobernante de Noruega y Dinamarca y en 1389 también de Suecia. Para obtener el apoyo alemán contra los duques de Mecklemburgo, quienes reclamaban el trono sueco, Margarita hizo elegir ley a su sobrino nieto, Erik de Pomerania.

Más tarde se produjo la unión con Dinamarca y Suecia. Por la Unión de Kilmar, en 1397, los tres reinos escandinavos se convirtieron en una sola unidad administrativa. Noruega pasó a ser una provincia de Dinamarca. La prosperidad noruega y su cultura fueron decayendo rápidamente después de la unión. A la decadencia del país se unió la peste negra, la plaga que asoló Noruega y el resto de Europa en el siglo XIV. Suecia y Dinamarca eran más ricas que Noruega, a la cual descuidaron en gran manera los Reyes escandinavos. Durante los cuatro siglos siguientes, Noruega permaneció estancada bajo el gobierno de los monarcas daneses.

Por último, las Guerras Napoleónicas condujeron a la disolución de la Unión de Kalmar.

Tras la derrota de Napoleón en 1814, Dinamarca, aliada de Francia, fue obligada a firmar el Tratado de Kiel, por el que cedía Noruega al Rey de Suecia. Sin embargo, los noruegos rechazaron el tratado, se declararon reino independiente, redactaron una Constitución liberal y ofrecieron la corona al príncipe heredero danés Frederick (que reinó con el nombre de Cristián VIII). Los poderes europeos no aprobaron esto y el mariscal Jean Baptiste Bernadotte, que posteriormente fue Rey con el nombre de Carlos IV, persuadió a Noruega de que aceptara el Tratado de Kiel; a cambio de su aceptación se permitió a Noruega mantenerla nueva Constitución que había promulgado. Mediante el Acta de Unión de 1815, el país contó 
con su propio ejército, marina, aduanas y poder legislativo, y se le permitió una total libertad y autonomía dentro de sus fronteras.

Después de 1814, la cámara legislativa noruega o Storting estuvo ocupada sobre todo en estabilizar y mejorar la condición financiera del país y en poner en marcha y salvaguardar su recientemente conseguido autogobierno. A pesar de una fuerte oposición por parte de Carlos XIV, monarca autocrático, en 1821 fue abolida la nobleza creada por los daneses; el Storting mantenía que los verdaderos nobles noruegos eran los campesinos descendientes de los barones. El nacionalismo noruego siguió creciendo y el Storting se quejó de que el trato sueco no estaba de acuerdo con el espíritu del Acta de Unión y con la condición de Noruega como un Estado semejante. Al final, en 1839, Carlos XIV nombró un Comité conjunto de suecos y noruegos para revisar los términos de la Unión; el

Rey Carlos murió en 1844, antes de que el comité remitiera su informe. Su hijo, Óscar I admitió la justicia de muchas de las peticiones noruegas y se hizo popular al conceder una bandera nacional para su marina, aunque llevara el símbolo de su unión con Suecia.

El movimiento liberal en la política de Noruega, que acompañaba al surgimiento del nacionalismo, se hizo más pronunciado tras las revoluciones de 1848 en los principales países de Europa. El nacionalismo político se vio reforzado por otro intelectual y cultural. Se comenzaron a recopilar mitos y canciones populares, se realizaran diccionarios históricos y gramáticas del noruego. El renacimiento literario contó con la aportación de figuras como Henrik Ibsen, Bjorn Isjet, lonas Lie y Alexander Krielland.

Cuando, en 1860, Suecia comenzó a proponer revisiones del Acta de Unión concediendo poderes adicionales, éstos fueron boicoteados por el grupo Venstre (Izquierda), creado tras la unión de los dos grandes partidos políticos noruegos, el Partido de los Abogados y el Partido de los Campesinos. Luego surgió otra importante controversia entre los dos países por los renovados intentos suecos de hacer una revisión constitucional, que establecería el derecho real a disolver el Storting. Encabezado por Johan Sverdrup, presidente del Parlamento, éste se enfrentó en una larga lucha contra el Rey Óscar I que tuvo que ceder en 1884. La política noruega se centró entonces en demandas sobre un servicio consular separado y una bandera noruega propia para la marina mercante, sin el símbolo de la unión. La bandera fue aprobada en 1898, pero Suecia rechazó la demanda de un servicio consular. En 1905, después de prolongadas negociaciones, el gobierno noruego renunció a su petición, pero el Storting rechazó a Óscar I como gobernante de Noruega y proclamó al país reino independiente. En 
el plebiscito de agosto de 1905 los noruegos votaron por una mayoría aplastante la separación de Suecia. El Parlamento sueco (Riksdag) ratificó la separación en octubre. Un mes más tarde, el príncipe Carlos de Dinamarca aceptó la corona noruega con el nombre de Haakon VII.

El gobierno noruego, dominado por ministros liberales, se convirtió en uno de los más avanzados de Europa en temas sociales tales como subsidios de desempleo, pensiones de jubilación y leyes que admitían numerosos derechos individuales, como el divorcio; en 1913 las mujeres noruegas obtuvieron el derecho a voto. Las mujeres desempeñan un importante papel en la política del país.

Tras el comienzo de la I Guerra Mundial, en 1914, los soberanos de Suecia, Noruega y Dinamarca acordaron declararse neutrales y cooperar para su mutuo interés. Esta política de neutralidad y amistad conjunta se prolongó tras la conclusión de la guerra. La depresión económica mundial que comenzó en 1929 afectó en gran manera a Noruega debido a su dependencia de las importaciones. El Partido Laborista se hizo con el poder en 1935 y continuó la política de moderación y liberalismo político que desde 1905 había dominado la vida política noruega.

El país mantuvo su neutralidad tradicional cuando en 1939 comenzó la II Guerra mundial. A pesar de su simpatía por Finlandia en su enfrentamiento con Rusia, Noruega rechazó una demanda franco-británica para permitir el paso de tropas en ayuda de Finlandia.

Sin embargo, la neutralidad noruega se hizo cada vez más difícil a causa del despliegue de la flota alemana a lo largo de la costa noruega. El 8 de abril de 1940, Gran Bretaña y Francia anunciaron que habían minado las aguas territoriales noruegas para impedir que los alemanes aprovisionaran allí sus barcos. Al día siguiente las fuerzas alemanas invadieron Noruega.

Con la ayuda del partido Nasjonal Samling (Unión Nacional) y oficiales desleales del ejército, los alemanes atacaron todos los puertos importantes. Vidkun Quisling, el dirigente del Nasjonal Samling, se autoproclamó jefe del gobierno noruego. Durante los años de guerra y ocupación, Haakon VII desempeñó un papel polifacético, participando en las situaciones y procesos en curso, en su calidad de símbolo unificador del pueblo. En la historia de la nación, y en los anales de la Monarquía figurará con brillo propio su rotundo "no" a las demandas alemanas de Quisling, el 10 de abril de 1940. Así se expresó el monarca ante los miembros de su Gobierno: "En vuestras manos está la decisión. Mas si decidís aceptar las 
demandas alemanas, me veré obligado a abdicar, pues yo no puedo nombrar a Quisling primer ministro."

En Nybergsund, aquel día de abril de 1940, renació el Poder personal del Rey. Después vendrían los largos años del exilio londinense, con el Gobierno representando al Estado noruego, sin un parlamento aliado; en la medida de lo posible, salvaguardando los intereses nacionales. Pero era el Rey quien, a la sazón, simbolizaba a la Nación. Con ello, el monarca contribuyó también a ensalzar, una vez más, a la Monarquía, en tiempos de profunda convulsión, como lo fue la II Guerra mundial.

La liberación en 1945 cementó el último eslabón de este proceso. La transición a un sistema político restituido tuvo lugar sin complicaciones: sorprendentemente sin acusaciones, si se tienen en cuenta los cinco turbulentos años vividos bajo tutela alemana. Casi automáticamente, Monarquía y monarca comenzaron de nuevo su función. Hasta los comunistas -a la sazón poderosos también en Noruega- tomaron parte en el homenaje rendido a Haakón VII a su desembarco en el muelle capitalino.

Por tanto, los líderes del movimiento de la resistencia noruega en el país cooperaron con el gobierno en el exilio de Londres, preparando una eventual liberación. Por último, el 8 de mayo de 1945 las fuerzas alemanas en Noruega se rindieron y el Rey Haakón regresó del exilio en junio. Para castigar a los colaboracionistas se restauró la pena de muerte, que había sido abolida en 1876. Quisling, junto a otros 25 noruegos, fue juzgado y ejecutado por alta traición.

El gobierno en el exilio dimitió al finalizar la guerra. El Partido laborista obtuvo la mayoría en las elecciones generales de octubre de 1945 y formó un gabinete presidido por Einar Gerhardsen.

Los laboristas se mantuvieron en el poder durante los siguientes veinte años. Bajo su administración Noruega fue evolucionando hasta configurar un Estado del bienestar muy avanzado; se convirtió en miembro fundador de las Naciones Unidas (ONU) en 1945, participó en el Plan Marshall en 1947 y en 1949 se unió a la Organización del Tratado del Atlántico Norte (OTAN). La pertenencia a la OTAN, fue aprobada tácitamente por los noruegos en las elecciones de octubre de 1949. La reconstrucción comenzó pronto, dirigida por el gobierno laborista, que asumió la planificación económica, reforzó la posición del país en los mercados internacionales: redistribuyó la riqueza nacional de forma más igualitaria. Este desarrollo estuvo acompañado por una nueva legislación social que incrementaba en 
gran manera el bienestar de los ciudadanos. En 1959 Noruega se convirtió en miembro fundador de la Asociación Europea de Libre Comercio (EFTA).

Olav V prosiguió en la misma línea a partir de 1957. Su padre tenía el estatuto de héroe de guerra, pero no era en modo alguno popular. Él fue el Rey del pueblo: esquiador, deportista de vela, ciudadano que pagó su propio billete de tranvía cuando las restricciones de gasolina causadas por la crisis del petróleo de 1974 inmovilizaron los vehículos de motor. Ni las dificultades de gobierno, ni las crisis nacionales pusieron el sistema a prueba. Los problemas cotidianos fueron resueltos sin fricciones. La Monarquía noruega tiene una base jurídica, la forma del Estado noruego no ha impedido la modernización de la sociedad, ni la posibilidad del Pueblo de elegir su propio destino sobre el plano político.

La democracia ha disfrutado de condiciones favorables para su florecimiento. La Monarquía ha sido un marco, no un freno, que se ha democratizado al menos tanto como la democracia se ha "monarquizado", en la Constitución escrita y en la no escrita. la muerte de Olav V, el dolor sentidos por innumerables personas eran sinceros; no sólo tristeza por la muerte de un anciano monarca, sino duelo personal por la pérdida de un ser querido por muchos.

En las elecciones parlamentarias que tuvieron lugar en septiembre de 1961 el Partido Laborista no alcanzó la mayoría de escaños por primera vez desde 1935, aunque mantuvo su condición de principal partido. Gertardsen, que había sido primer ministro desde el final de la guerra, excepto en un intervalo desde 1951 a 1955, fue nuevamente designado jefe del gabinete. En 1965 el Partio Laborista fue derrotado en las elecciones generales. El Rey Olaf V, que había sucedido a Haakón VII cuando éste murió en 1957, pidió a Per Borten, jefe de la coalición de fuerzas conservadoras que formara gobierno.

La política económica, sin embargo, no cambió de una manera excesiva.

En 1970 Noruega solicitó su ingreso en la entonces denominada Comunidad Económica Europea o CEE (hoy Unión Europea o UE), lo que dio lugar a una mayor disensión dentro del gobierno. A comienzos del año siguiente Borten dimitió. Trygve Bratteli, del Partido Laborista, formó entonces un gobierno minoritario que hizo una fuerte campaña en favor de la pertenencia a la CEE. Sin embargo, los resultados de un referéndum celebrado en 1972 fueron contrarios a la recomendación del Gobierno. Bratteli dimitió y fue sucedido por una coalición centrista liderada por el democristiano Lars Korvald. En mayo del 1973 Noruega firmó un acuerdo de libre comercio con la CEE. Los laboristas tuvieron pérdidas importantes en las elecciones de 1973, pero de nuevo Bratteli pudo formar un gobierno de minoría. 
Los laboristas siguieron en el poder hasta las elecciones celebradas en septiembre de 1981, bajo la jefatura de Gro Harlem Brundtland, la primera mujer que se convirtió en primera ministra. Los partidos conservadores obtuvieron una aceptable mayoría en esas elecciones y Kare Willoch formó un gobierno de coalición en octubre. En 1983 se formó la coalición más amplia, encabezada de nuevo por Willoch, que en 1985 fue reelegida otra vez. El Rey Olaf V murió en enero de 1991 y le sucedió su hijo, Harald V. En 1993, diplomáticos noruegos encabezados por el ministro de Asuntos Exteriores, Johan Holst, desempeñaron un papel crucial en las negociaciones de paz entre Israel y la Organización para la Liberación de Palestina; Holst murió en enero de 1994. Los XVIII Juegos Olímpicos de Invierno se celebraron en Lilleharnmer en febrero de 1994. El 4 de mayo de 1994, el Parlamento Europeo aprobó el ingreso en la Unión Europea de Noruega, Suecia, Finlandia y Austria. Las negociaciones con Noruega se habían estancado antes debido a una disputa sobre los derechos de pesca en las aguas territoriales noruegas del mar del Norte.

Sin embargo, en un referéndum que tuvo lugar el 27 y el 28 de noviembre de 1994, los noruegos rechazaron por segunda vez su entrada en la UE, a pesar de una fuerte campaña por parte de Brutland.

La economía del país se mantuvo en unos buenos niveles a lo largo de 1995. El índice de desempleo bajó, y al final de año Noruega había saldado totalmente su deuda externa. Pese a la popularidad de Brundtland, el 23 de octubre de 1996 presentó su dimisión al parlamento y fue sustituida por el laborista Thorbjoen JagJand, que sigue unas directrices políticas semejantes a las de su predecesora en el cargo.

\subsection{Dinamarca}

La Casa Real danesa se remonta a Gorm el Viejo (enterrado el año 958 en Jelling, Jutlandia) y a su hijo, Harald I Diente Azul, quien trasladó la sede de la Monarquía a Selandia. Estos dos Reyes son los primeros que con seguridad pueden relacionarse, histórica y geográficamente, con la unificación de Dinamarca. La Monarquía era electa y limitada a la familia real, aunque no a la línea masculina. Así, Svend II Estridsen era el hijo de la hermana de Canuto II el Grande. La Casa Real alcanzó su primer apogeo en la época de los Reyes llamados Valdemar, ya que su influencia se extendió a la mayor parte del Báltico, y más tarde, con Margarita I, quien unificó los países nórdicos mediante la Unión de KalmaJ. 
En 1448, después de la extinción de la descendencia directa, el conde Christian de Coldenburg fue elegido Rey de Dinamarca bajo el nombre de Christian I, además de duque de Schleswig y conde de Holstein. Su parentesco con la Casa Real era de seis generaciones, tres de ellas por línea femenina. Sus descendientes directos, la dinastía de Oldenburg, reinaron bajo los nombres de Christian y Frederik, alternativamente, desde la elección de Federico I el año 1523, y hasta que Federico VII murió sin descendencia el año 1863. La Monarquía electa perduró hasta los años 1660-1661, cuando Federico III instauró una Monarquía hereditaria para Dinamarca y Noruega. Los artículos de la Ley Real que regulaban el estatuto de la Casa Real siguieron vigentes después de que la Constitución del 5 de junio de 1849, bajo el reinado de Federico VII, instauró la Monarquía constitucional.

El príncipe Christian de Glücksburg, descendiente por línea directa de la Casa Real, sucedió a Federico VII a la muerte de éste el año 1863, bajo el nombre de Christian IX. De esta forma, el trono pasó a la línea de los Glücksburg.

Christian IX recibió el sobrenombre de suegro de Europa, ya que su hija Alejandra estaba casada con el Rey de Inglaterra, Eduardo VII, su hija Dagmar, con el emperador de Rusia, Alejandro III, y su hija Thyra, con el duque de Cumberland, Emest August. Cuando también el hijo de Christian IX, Wilhelm, fue nombrado Rey de Grecia, bajo el nombre de Jorge I, en el año 1863, una gran parte de las casas reales europeas acudían a las reuniones familiares de Christian IX en el palacio de Fredensborg. En el año 1905, su nieto Carlos fue nombrado Rey de Noruega bajo el nombre de Haakón VII.

Federico VIII sucedió a su padre el año 1906, pero su reinado fue corto ya que murió en 1912. Su hijo mayor, Christian X, reinó hasta 1947 inscribiéndose en la historia como el Rey que en el año 1920 cruzó a caballo la frontera del sur de Jutlandia cuando esta provincia, perdida en 1864, fue devuelta a Dinamarca. En él también se centró el sentimiento nacional durante la ocupación alemana de 1940-1945.

Su hijo mayor, Federico IX, se casó en 1935 con la princesa Ingrid de Suecia, hija del Rey Gustavo Adolfo VI. Ascendió al trono en 1947 y su reinado consolidó la Monarquía constitucional, al aceptar que el Rey no tendría poder político. En tanto que jefe de Estado, el monarca regente interviene en la formación del gobierno y formalmente encabeza el gobierno y representa a Dinamarca en el exterior. La comprensión que la Casa Real ha demostrado por estas circunstancias así como el contacto estrecho que han construido con la población, han hecho que su posición esté profundamente arraigada y fuera de toda 
discusión, en un tiempo en que las casas reales de otros países han provocado un debate sobre la necesidad de la Monarquía como institución.

El derecho de sucesión de la línea de Glücksburg fue confirmado por última vez mediante la Ley de Sucesión del 27 de marzo de 1953, que otorga el derecho al trono a los descendientes de Christian X. Según la ley, los hijos preceden a las hijas, aunque si no hay hijos, sucederá la hija mayor. La princesa Margarita pudo así acceder al trono tras la muerte de su padre en 1972 y, bajo el nombre de Margarita II, convertirse en la primera mujer en el trono desde la muerte de Margarita I el año 1412.

La reina Margarita II, que el 10 de junio de 1967 contrajo matrimonio con Henrik, príncipe de Dinamarca, nacido Henri Marie Lean André, Conde de Laborde de Monpezat, en Francia, accedió al trono el 14 de enero de 1972. La pareja real tiene dos hijos, el príncipe heredero Federico y el príncipe Joachim; éste último casado con Alexandra Christina Manley, con quien tiene un hijo llamado Nikolai William Alexander Frederik.

La Reina tiene dos hermanas, la princesa Benedicta, que está casada con Richard, príncipe de Sayn-Wittgenstein-Berleburg, de Alemania, y la princesa Ana-María, que está casada con Constantino, ex Rey de Grecia.

Margarita II, cuando nació, no podía legalmente acceder al trono, pero la revisión de la Constitución que tuvo lugar en 1953 a raíz de un referéndum, que dio lugar a la posibilidad de una sucesión femenina al trono. El día en que cumplió los dieciocho años, Margarita, princesa heredera, fue admitida en el Consejo de Estado.

Pertenece al Cuerpo Femenino de las Reales Fuerzas Aéreas danesas. De 1960 a 1965, frecuentó las universidades de Copenhague, Cambridge, Arhus, la Sorbona y Londres, centrándose sobre todo en los estudios de Ciencias Políticas y Arqueología.

La Reina ha realizado traducciones y ha practicado varios géneros artísticos. Como diseñadora y bordadora artística, la Reina ha creado capas episcopales así como casullas. Como grabadora, la reina Margarita II ha ilustrado un gran número de libros y, además, ha diseñado los trajes para el espectáculo televisivo 'La pastora y el limpiachimeneas' (1987). Una de las obras más importantes realizadas por la Reina es la escenografía para el ballet 'Una leyenda popular' (1991).

El príncipe heredero Federico, entre 1998 y 1999 asumió las funciones de secretario en la embajada danesa en París, y en el otoño del año 2000 terminó una carrera en el Ejército del Aire. Al alcanzar la mayoría de edad, 18 años, entró a formar parte del Consejo de Estado. 


\subsection{Suecia}

Desde mediados del siglo XII, los feudos de Sverkery de Erik lucharon por el control del reino sueco y se alternaron en el poder entre 1160 y 1250. Los señores conservaron bastante autonomía hasta la mitad del siglo XIII, cuando el Rey impuso leyes en todo el país, al que se agregó Finlandia.

En 1350, la peste negra provocó una larga recesión, no superada hasta mediados del siglo $\mathrm{XV}$, cuando las fundiciones de la región central adquirieron importancia. En los siglos XV y XVI, la Hansa alemana dominó el comercio con Suecia y estimuló la fundación de varias ciudades.

Por herencia y relaciones entre linajes, el poder real de Noruega, Suecia y Dinamarca. Se concentró en la reina danesa Margarita, quien en 1397 decretó la Unión de Kalrnar. Los sucesivos conflictos entre el poder central danés y la nobleza, así como con ciudadanos y campesinos rebeldes suecos, culminaron en 1523, con la elección de Gustavo Vasa como Rey de Suecia.

En el reinado de Vasa, la Monarquía pasó de electiva, en que la nobleza hacía oír su voz, a hereditaria; la administración adoptó el modelo alemán y se sentaron las bases del Estado nacional. Las posesiones de la Iglesia pasaron al Estado y acto seguido se realizó la reforma protestante. Desde entonces, Suecia aspiró a la hegemonía en el Báltico.

A la muerte de Carlos XII, ocurrida en 1718, el Par1amento de los nobles abolió el absolutismo y asumió el poder, pero el nuevo Rey, Gustavo II , dio un golpe de Estado en 1772 y restableció el absolutismo en 1789.

Durante las guerras napoleónicas Suecia se apoderó de Finlandia y el regente Carlos XIV Juan, elegido en 1810, consiguió que se le cediera Noruega como compensación por las pérdidas sufridas. Tras una corta guerra de resistencia, Noruega se vio obligada a unirse con Suecia en 1814. Sin embargo, después de numerosos conflictos, la unión se disolvió pacíficamente en 1905 y Noruega ganó su independencia.

\subsection{Comparativa de las Monarquías de los Países Nórdicos, Bélgica y Holanda.}


La Monarquía ha pasado, históricamente, de ser una forma de Estado a ser una forma de la jefatura del Estado. En aquellos sistemas en los que hay una participación del monarca en la soberanía, la Monarquía es una forma de Estado. Cuando se parte del reconocimiento de la soberanía popular, entonces, la Monarquía no es nada más que una opción posible en la configuración de la jefatura del Estado. Ahora bien, si la Monarquía quiere sobrevivir en el marco de la soberanía popular, ha de ser parlamentaria.

En la transición desde la Monarquía absoluta hasta la Monarquía parlamentaria, han existido formas intermedias que, en ocasiones, se tratan indiferenciadamente, pero que conviene distinguir: la Monarquía limitada y la Monarquía constitucional. En la Monarquía limitada sobrevive el principio monárquico y la Constitución es otorgada (Constitución francesa de $1814 \mathrm{y}$, en la medida en que pueda considerarse Constitución, nuestro Estatuto Real de 1834) y pactada (Constitución francesa de 1830, Constituciones españolas de 1845 y 1876), lo que significa que, de alguna forma, la Monarquía sigue siendo en este supuesto una forma de Estado. En la Monarquía orleanista (Constitución francesa de 1830 y Constitución belga de 1831, que algunos autores llaman también Monarquía constitucional), hay una participación del Rey en el poder ejecutivo, que tiende a ejercerse de forma parlamentaria, y no hay participación del monarca en el poder constituyente.

Las Monarquías europeas continentales no forman un conjunto muy homogéneo.

Es quizá el limitado tamaño de las mismas, así como la característica común de tener una jefatura del Estado monárquica, casi lo único que justifica la inclusión de todas ellas en un mismo epígrafe.

Con frecuencia, esas Monarquías han partido de un texto que configura una Monarquía de tipo limitado para evolucionar, de forma consuetudinaria, hacia un funcionamiento parlamentario que, finalmente, es recogido en un nuevo texto constitucional. Intentando clasificarlas en función de su mayor o menor acercamiento a la Monarquía limitada, atendiendo al texto constitucional vigente, cabría establecer la siguiente gradación: la más cercana a la Monarquía imitada sería la noruega; hasta 
1993, la segunda más próxima a tal modelo era la belga, que ahora podríamos quizá considerar más parlamentarizada que Holanda; la siguiente nación sería Dinamarca, que actualizó su texto en 1953; la seguiría Holanda con el texto actualizado en 1987; después, España (Constitución de 1978); y, el grado máximo de racionalización del carácter parlamentario de la Monarquía, lo ofrecería la Constitución sueca tras su modificación de 1974.

Las Monarquías parlamentarias presentan similitudes como consecuencia de la limitación constitucional y de analogía de contextos políticos, y han demostrado que el parlamentarismo monárquico es posible, también, fuera de Gran Bretaña.

Son condiciones de formación del régimen parlamentario unas determinadas características políticas y jurídicas.

En cuanto a las primeras, hay una cierta diferencia entre Escandinavia, por una parte, y Bélgica y Holanda, por otra. En los países escandinavos, el constitucionalismo concilia la tradición monárquica con el liberalismo (constitución sueca de 1809, noruega de 1814, danesa de 1849). En Holanda (1815) y en Bélgica (1831) la aparición del constitucionalismo significa, simultáneamente, el acceso a la independencia.

Originariamente, los textos constitucionales de estos países no establecen un sistema parlamentario sino una Monarquía constitucional o limitada. Todas ellas recogen una articulación de los poderes derivada de la versión de Montesquieu sin perjuicio de algunas peculiaridades. Ni siquiera la responsabilidad política de los Ministros o del Gabinete quedaba recogida en esos textos constitucionales; todo lo más podríamos encontrar en alguno el reconocimiento de un 1 responsabilidad de carácter judicial. Ahora bien, la Monarquía limitada, como los organismos, no pueden ser sino sistemas de transición.

En todos estos países, el funcionamiento parlamentario (Bélgica en 1831, Holanda en 1848, Noruega en 1884, Dinamarca en 1901, Suecia en 1909) es anterior a la democracia si aceptamos convencionalmente como momento de implantación de la misma la del sufragio universal (en 1919 en Bélgica y en Holanda, 1913 en Noruega, 1915 en Dinamarca y 1921 en Suecia). 
Las reformas constitucionales escritas recogen con frecuencia, prácticas o costumbres de carácter parlamentario anteriores a ellas. Por la propia naturaleza de las costumbres, resulta difícil señalar en qué momento aparecen. El momento en que surgió la responsabilidad política sólo está claro en Noruega (1884); en cambio, sí se puede señalar el momento en que se escoge como Primer Ministro al que cuenta con mayoría parlamentaria (Suecia en 1917, Noruega en 1884, Dinamarca en 1901), y, a veces, sólo se puede conocer la última ocasión en que el Rey actuó de forma no parlamentaria: el último Gobierno cesado por decisión del Rey en Dinamarca fue en 1920.

El Rey y su relación con el Gobierno. El Rey aparecía en las Constituciones como jefe del poder ejecutivo, lo que conllevaba potestad reglamentaria, poder de nombramiento y cese de los Ministros, dirección de la: relaciones exteriores, e incluso participación en el poder legislativo. Si nos atenemos a los textos actuales, ni la Constitución holandesa ni la sueca le atribuyen el poder ejecutivo pero sí lo hacen la belga, la danesa o la noruega. Aunque el texto le atribuya el poder ejecutivo para precisar el carácter parlamentario del sistema, ha de analizarse hasta qué punto el Consejo de Ministros está emancipado del Rey, así como la extensión de la regla del refrendo. Todas las decisiones del Rey deben ser tomadas en Consejo de Ministros y todas las Constituciones dicen que el Rey nombra y cesa a los Ministros, si bien la forma más enérgica que podemos encontrar es la holandesa. La extensión del refrendo no es la misma en todos los sistemas y no se puede descartar, en concreto en Bélgica o en Dinamarca, si nos atenemos al texto escrito, la posibilidad de una negativa; mientras que, en otras, la negativa sería contraria al propio texto escrito (Suecia).

Según el artículo 96 de la Constitución belga de 1993, el Rey nombra y revoca a sus Ministros. El Gobierno federal presenta su dimisión al Rey si la Cámara de representantes, por mayoría absoluta de sus miembros, adopta una moción de censura que proponga al Rey el nombramiento de un sucesor al Primer Ministro en los tres días siguientes al rechazo de una cuestión de confianza. El Rey nombra 
Primer Ministro al sucesor propuesto, que entra en funciones en el momento en que el nuevo Gobierno federal preste juramento.

El Rey y su relación con el Parlamento. El Parlamento es unicameral en Suecia y en Dinamarca, bicameral en Holanda y Bélgica y tiene una naturaleza peculiar en Noruega donde, celebrándose una sola elección, se procede después, por un artificio, a dividir la representación nacional en dos Cámaras: el Lagting (una cuarta parte de los miembros del Parlamento) y el Odelsting (el resto de los miembros del Parlamento).

Los parlamentarios gozan de inmunidad e inviolabilidad, con alguna rara excepción, y son remunerados. El Parlamento tiene atribuida la función legislativa en tales términos que, en algún caso, se prohíbe la delegación.

En algunos de estos países, la mayoría de los miembros del Gobierno son miembros del Parlamento; pero en otros su presencia en el mismo es dificultada no sólo de hecho sino, incluso, jurídicamente (en Noruega, en Holanda y últimamente en Bélgica).

El veto del Rey a los textos legislativos subsiste en alguna Constitución pero, cuando es así, está decididamente en desuso o, en caso de resistencia regia a la aprobación de una ley, ésta es anunciada con anterioridad a la presentación del proyecto de ley ante el Parlamento, con lo cual no trasciende ante la opinión pública.

Relación Rey-Parlamento-Gobierno. La responsabilidad política de los Ministros es formulada en el artículo 15 de la Constitución danesa, pero no en la holandesa. En la sueca y en la noruega parece aludirse más bien a la responsabilidad judicial, pero en este punto siguen rigiendo de forma considerable normas de carácter consuetudinario.

El derecho de disolución, que algunos constitucionalistas muy autorizados no consideran esencial para el parlamentarismo, sí lo es; y buena prueba de ello es que cuando desaparece de los textos constitucionales o caen en desuso, la forma de gobierno pasa a tener un funcionamiento de tipo asambleario. El derecho de 
disolución está previsto en todos los textos constitucionales, salvo en Noruega, y es atribuido al Rey.

En los bicamerales pueden ser disueltas las dos Cámaras de forma separada o de forma simultánea. En todos los países la decisión de la disolución corresponde formalmente al Rey.

La reciente Constitución belga de 1993 ha procedido a una revolución del parlamentarismo, no ya simplemente racionalizada, sino algo alambicada. Según su artículo 46, el Rey sólo tiene el derecho de disolver la Cámara de representantes si ésta, por mayoría absoluta de sus miembros:

- Bien rechaza una cuestión de confianza al Gobierno federal y no propone al Rey, en un plazo de tres días a contar desde el día del rechazo de la cuestión, el nombramiento del sucesor al primer Ministro;

- Bien adopta una moción de censura respecto del Gobierno federal y no propone, simultáneamente, al Rey el nombramiento de un sucesor al Primer Ministro.

La moción de censura y la cuestión de confianza no pueden ser votadas sino después de un plazo de 48 horas siguientes a la presentación de la moción. Además, el Rey puede, en caso de dimisión del Gobierno federal, disolver la Cámara de representantes después de haber recibido su consentimiento, expresado por mayoría absoluta de sus miembros.

La disolución de la Cámara de representantes conlleva la disolución del Senado.

\subsection{Gran Bretaña}

Durante el siglo V, los habitantes de Irlanda y Gales adoptaron el cristianismo. En el siglo VII, el poder de Roma se impuso sobre la iglesia británica.

En los siglos VII y IX, los daneses invadieron la región oriental de Inglaterra. En el siglo XI, los normandos, liderados por Guillermo el Conquistador, invadieron la isla e impusieron su 
hegemonía. Los Reyes anglonormandos desarrollaron una poderosa administración y dominaron dos alzamientos de los antiguos nobles sajones.

El prestigio ganado por el Rey Ricardo Corazón de León (1189-1199), uno de los caudillos de la Tercera Cruzada, se desmoronó bajo el reinado de su sucesor Juan Sin Tierra (1199-1216). Inglaterra perdió sus territorios franceses (hasta bien entrado el siglo XX, el diario Times de Londres titulaba a los Reyes de Inglaterra como Reyes de Francia) y los barones, en alianza con el clero, aprovecharon la debilidad de la corona para obtener algunas reivindicaciones en la Carta Magna de 1215. Siendo la segunda de Europa tras la de León (1188), aunque la inglesa más extensa.

Este documento sentó las bases del parlamentarismo británico. A partir de entonces se libró una lucha permanente por el poder entre la Monarquía y la nobleza, a la cual se unió posteriormente la burguesía. El parlamento representaba los intereses de estas clases y se llegó finalmente a la consolidación de una Monarquía parlamentaria.

Los frecuentes conflictos dinásticos, las aspiraciones de la corona británica al trono francés, la rivalidad comercial de estas dos naciones en Flandes y el apoyo prestado por Francia a Escocia en sus guerras con Inglaterra, provocarán la Guerra de los Cien Años (1337-1453), que culminó con la derrota británica y la pérdida de sus posesiones en el continente.

Los fracasos militares aumentaron el desprestigio de la corona, que tuvo que enfrentare al movimiento antipapal de los seguidores de Wycliffe (antecesor de Lutero) y una rebelión campesina. Los campesinos, comandados por Wat Tyler se rebelaron contra el pago de tributos y el poder de los señores feudales. En 1381, Tyler y su tropa lograron entrar en Londres y negociar directamente con el Rey. Sin embargo, la rebelión campesina no tuvo éxito, y Tyler fue ejecutado.

En la etapa posterior a la Guerra de los Cien Años, la disputa dinástica entre los

Lancaster y los York desencadenó la guerra de las Dos Rosas, que culminó con el ascenso al poder de los Tudor en 1485. El periodo de los Tudor es considerado el comienzo del moderno Estado británico. Uno de los Tudor, Enrique VIII (1509-1547) rompió con Roma, confiscó todos los monasterios y fundó la Iglesia Anglicana. El deseo de extender la autoridad inglesa y la reforma religiosa a Irlanda hicieron que la sucesora de Enrique, Isabel I (1558-1603), impusiera su dominio en el Ulster. La invasión de Irlanda por parte de los Tudor dio origen a dos siglos de conflicto político y religioso. 
Bajo el reinado de Isabel I florecieron la poesía y e 1 teatro (Ben Jonson, Marlowe, Shakespeare), se desarrollaron la industria y el comercio, y se inició la aventura colonial, embrión del futuro imperio. Luego de vencer a la flota española -la llamada Armada Invencible por ellos irónicamente y Gran Armada por la nuestra- en la batalla de Trafalgar (1805), la marina británica se convirtió en la "dueña de los mares", sin que hubiese flota capaz de oponérsele.

Los barcos mercantes ingleses, los que se usaban para el tráfico de esclavos, los piratas y corsarios, o los buques con nuevos colonos, surcaron libremente los océanos. Los mercados se multiplicaron, la demanda creció rápidamente y los productores se vieron obligados a emplear nuevas técnicas para acelerar su producción. Fue el prólogo de la revolución industrial que se desarrolló en el país a partir del siglo XVIII.

La unión en Jacobo I (1603-1625) de la corona de Escocia y de Inglaterra puso fin a la independencia de la católica Monarquía escocesa. La intolerancia religiosa de Carlos 1, hijo de Jacobo, provocó una rebelión en Escocia y creciente descontento en Inglaterra. El deterioro de la situación política llevó al partido puritano, con el apoyo del Parlamento, a armar su propio ejército, dirigido por Oliver Cromwell, que en 1642 derrotó a las fuerzas reales. En 1649, el Parlamento condenó a muerte al Rey y proclamó a Cromwell Lord Protector, instituyendo la república de la Commonwealth (Comunidad), que se convirtió en un régimen despótico. Tras su muerte, se restauró la Monarquía en 1658, con Carlos II.

El nuevo régimen impulsó la colonización de Norteamérica y el comercio con América, Extremo Oriente y el Mediterráneo. La trata de esclavos -secuestro, tráfico y venta de africanos a América y otros lugares- iniciada en el siglo XVI, se convirtió en una de las principales fuentes de ingreso del imperio.

La política absolutista de Jacobo II y su profesión de fe católica chocaron con el

Parlamento protestante y provocaron la Revolución Gloriosa. El Rey huyó a Francia y los protestantes invitaron al holandés Guillermo de Orange a asumir el trono. En 1689, Guillermo juró sobre la Declaración de Derechos, que limitó los poderes reales y aseguró la supremacía del Parlamento.

En el largo período de la reina Victoria (1837-1901), la nobleza estrechó su alianza con la burguesía industrial y mercantil y surgieron los prime los movimientos socialistas. Los sindicatos obtuvieron su legalización en 1871. Poco después se aprobaron nuevas leyes laborales. 


\subsubsection{Poderes constitucionales monárquicos}

En una de sus acepciones, el término Corona es homólogo al término Estado en Derecho continental. En tal sentido, la Corona representa la unidad de los poderes jurídico-políticos: el Poder ejecutivo es el "Rey en consejo"; el legislativo, el "Rey en Parlamento" y el judicial, el "Rey en su Tribuna". Cumple, en fin, la misión de la personalidad jurídica del Estado en el continente: se le imputan actos administrativos y judiciales; se diría que la Corona lo hace todo.

Además la Corona, en sentido técnico-constitucional, es irresponsable civil, penal y hasta políticamente, lo que se expresa con el principio del "Common Law" (Ley Común) "the King can do no wrong" ("El Rey no puede equivocarse").

Intentando precisar más las atribuciones concretas de la Corona, la doctrina distingue entre las atribuidas por el "Common Law" y por el Derecho legal.

La prerrogativa es "la especial preeminencia que le tiene el Rey en virtud del "Common Law", pero al margen de su curso ordinario y en virtud de su dignidad real".

Como el Derecho legal limita (o concreta) esos poderes regios, la prerrogativa se define como "el residuo de la autoridad discrecional o arbitrario que en un tiempo dado está jurídicamente en manos de la Corona".

En la actualidad, la prerrogativa viene limitada a la designación de Primer Ministro cuando la voluntad parlamentaria o electoral no sea clara. Esto puede suceder cuando no haya una mayoría homogénea o cuando no haya un claro líder de la mayoría.

Lo primero ocurrió entre 1919 y 1935, años durante los que un nuevo partido, el laborista, se abría paso para sustituir al liberal; lo segundo tuvo lugar en 1957, cuando A. Eden dimitió tras la desafortunada expedición de Suez. O en 1963, cuando MacMillan se retiró. 
Todas las restantes atribuciones que incluye la prerrogativa han de ser ejercidas con refrendo, y no puede ser de otra manera: la prerrogativa y la irresponsabilidad regia, en un sistema democrático, implican refrendo.

Las atribuciones que ejerce el Rey (o Reina) con refrendo alcanzan y hasta desbordan las tres funciones clásicas del Estado:

- En el orden legislativo, el Rey reúne el Parlamento anualmente, tanto por convención como por la necesidad de aprobarlos Presupuestos y lo disuelve (convocándolo de nuevo en el plazo de tres meses). Sanciona las leyes, y puede nombrar Pares.

- En el orden ejecutivo, es Jefe supremo de las Fuerzas Armadas (como D. Juan

- Carlos I en España), cuida la paz y seguridad de Reino, es fuente de honor y merced (confiere títulos y honores) y le corresponden los llamados "actos de Estado" (relaciones diplomáticas, declaración de guerra y conclusión de la paz, reconocimiento internacional, manifestación del consentimiento a los Tratados).

- En el orden judicial, se le considera origen de toda jurisdicción y en consecuencia, puede detener un proceso (la decisión la toma el Fiscal General) y ejerce el derecho de gracia.

- Además, los tratadistas lo consideran "guardián de la Constitución". Tiene poderes que desbordan las funciones estatales: es Gobernador de la Iglesia anglicana y protector de los seres indefensos; y la Familia Real ha de ser ejemplo de todas las familias. En este ámbito, la institución es objeto de revisión en la actualidad.

Se está estudiando la posibilidad de que el Rey deje de gobernar la Iglesia anglicana, de suprimir el requisito de la confesionalidad a los miembros de la Familia Real, de que la Corona deje de percibir la cuantiosa suma que le asignan los Presupuestos Generales del Estado, de que sus propiedades dejen de estar exentas fiscal mente, y 
es que la Corona inglesa busca mantener su ejemplaridad. Acaso la Monarquía inglesa ha cargado demasiado las tintas en su ejemplaridad como justificación de su supervivencia. En la actualidad pasa por un momento extremadamente delicado.

\section{Conclusiones}

Tal y como hemos podido comprobar en las evoluciones históricas de todas las Monarquías tomadas como referencia en nuestro marco geográfico cercano, Europa, la figura del Rey ha evolucionado desde su origen más o menos divino (por la Gracia de Dios) hasta convertirse en monarca constitucional. La frase 'El Rey reina pero no gobierna' es la que mejor se ajusta a la realidad actual.

Por ello, la mayoría de las labores de los Reyes europeos de hoy en día se ubican en el ámbito de la representación de su país en el exterior, de consolidación de las instituciones democráticas (convocatoria de Parlamentos, papel mediador entre rivales políticos...) y la jefatura de las Fuerzas Armadas para evitar asonadas, tan propias en otras épocas.

Esta función de atemperamiento de fuerzas, muchas veces centrípetas, supone que la figura real se apoye en la imagen que sus súbditos (que no vasallos) tengan de la necesidad de la misma.

El siglo XXI principia con Monarquías en los principales países europeos, los de renta per cápita más alta y los que se han constituido como referentes en modelos sociales. En los países antiguas Monarquías, el paso a la República como forma de Estado ha venido derivado de guerras, en especial las dos mundiales, que se llevaron por delante la rusa, la alemana, la italiana, la rumana, la austro-húngara, la búlgara, la turca y la yugoeslava, en especial.

El caso de Francia, Monarquía secular, deriva de su Revolución y la guerra franco-prusiana (1870), la portuguesa (1910) por golpe de estado militar, la griega (1973) por golpe de estado militar (1967) apoyado por el Rey Constantino II que le costó la corona cuando trató de organizar otros en su contra y más tarde por referéndum se declaró oficialmente la República (1974) y la polaca por invasiones alemanas y rusas (1795).

En su detrimento, existen muchos movimientos republicanos en estos países que consideran que no es compatible con la democracia una Monarquía hereditaria, cuya familia rectora no 
fue elegida directamente por el pueblo en ningún momento de su historia y que ni tan siquiera ha sido votada actualmente, las más de las veces, como modelo de Estado. De hecho en los dos referendos más significativos, Italia y Grecia, la República ganó.

Este posicionamiento de la figura del Monarca como mediador político e imagen de país es el que actualmente sostiene popularmente a la institución. Es muy importante para su mantenimiento no transgredir las líneas rojas de inmiscuirse en la política nacional decantándose por una u otra opción partidista ni hacer ostentación de riqueza, creación de 'cortes' de acólitos o abuso de poder por parte de sus miembros. Positivamente estabilizan y dan garantía de continuidad democrática y sirven de referencia de contacto para las potencias extranjeras.

El presente artículo que hemos realizado acerca de las características político-jurídicas de la Monarquía en España y la comparación que hemos realizado con las constituciones tanto pasadas como presentes, nos ha dejado una serie de conclusiones que vamos a exponer:

- El Rey es la máxima representación del Estado español tanto a nivel nacional como internacional. Su función es la de reinar pero no propiamente la de gobernar.

- La figura del Rey es algo cuasi intocable, es una figura que no está sujeta a responsabilidad, por lo tanto, de sus actos son responsables directos aquellos que lo han refrendado. Esto tiene que ver con dos principios que siguen, vigentes en nuestra constitución y cuyo origen se encuentra en la Edad Media. Dichos principios son los de Irresponsabilidad y el de Institución de Refrendo.

- Desde luego estos principios no tienen mucho sentido en nuestros días y más teniendo en cuenta que se trata de una institución que se basa en la tradición, se asienta en principios procedentes de la Edad Media y, en muchos casos, en privilegios algo obsoletos.

- No parece lo más lógico que un cargo de tanta relevancia como es el de Rey no rinda cuentas de sus actos como un político más, sin embargo, esto habría que encuadrarlo dentro del papel real que el Monarca tiene en nuestro país. En nuestro caso, el papel es el de reinar pero no el de gobernar. Esto quiere decir que su misión principal es la de ser el máximo representante de nuestro país 
en todos los ámbitos. También es cierto que sus actos para ser válidos han de estar respaldados por el Gobierno de turno y no dependen de su voluntad personal.

- Por ello, el Rey es el jefe del Estado español, es quien tiene la última palabra en todas las decisiones y se encarga de velar la constitución.

- El Rey es responsable directo del nombramiento de los cargos de su casa, su cargo es hereditario aunque la persona que tiene derecho a su cargo contrajese matrimonio contra la voluntad real, este perdería el trono para su persona y la de sus descendientes.

- Además hay que tener en cuenta que nuestro país muchas corrientes de opinión manifiestan que la Monarquía es algo que ha quedado obsoleto y que no tiene mucho sentido en nuestros días, de modo que la constitución trata de proteger en la medida de lo posible a dicha institución que se considera vital para el correcto funcionamiento de la Democracia.

- Desde luego se trata de una institución que funciona con elementos tradicionales heredados desde la Edad Media, incluso en el que se hallan elementos discriminatorios como la Ley Sálica (en caso de igualdad de derechos sucesorios prevalece el hombre a la mujer, lo que llevará al trono a Felipe VI en vez de a su hermana, hipotética Helena I) que puede constituir el mayor elemento machista que pueda existir en una sociedad y que será en breve refutado mediante una nueva Pragmática Sanción a través de una reforma constitucional. Ésta no se ha llevado a cabo por el momento ya que la segunda en la sucesión al trono, la Infanta Doña Leonor De Borbón, tras su padre, futuro Felipe VI, va a tener en unos meses un hermano/a. De ser varón sí sería precisa la reforma y de ser hembra, no. También influye el hecho de que esta modificación constitucional podría ser entendida como un referendo a la Monarquía en su totalidad.

- Sin embargo, la Monarquía es una institución que, en nuestro país, se asocia a un cambio democrático positivo en el que dicha institución desempeñó un papel importante a la hora de asentar la democracia tras largos años de 
dictadura militar y ese papel de representante del estado español es muy valorado.

- Por otro lado, llama la atención como sigue funcionando una institución que va en contra de todos los criterios democráticos. Un pueblo no elige a su Rey ni a su Casa Real, este hereda su rango de su padre y así sucesivamente, además en caso de que se produjera alguna alteración en la sucesión siempre acabaría detentando el cargo quién en última instancia designara hereditariamente el Rey y sólo en caso de que se cortara totalmente la sucesión, las Cortes elegirían el representante más adecuado. El Rey tiene todo el poder a la hora de nombrar los cargos de su casa, es la máxima representación del Estado español y es quien en última instancia, aunque sea de modo simbólico, acepta o no las decisiones que se tomen.

- Es curioso observar como en esta época en la que prima, ante todo, el tema de la globalización o mundialización en todos aspectos, la Monarquía sigue siendo ante todo una institución nacional. Representa a un estado concreto y además hay aspectos como que el tutor del futuro Rey será quien decida el Rey, pero siempre que este sea mayor de edad y español. Este es un aspecto sobre el que se puede reflexionar un poco más acerca de si la Monarquía es o no una institución obsoleta en nuestros días.

- Tampoco la labor de Rey supone una libertad absoluta en su propia vida ya que, por ejemplo, el heredero legítimo al trono puede perder su cargo en su persona y en la de sus descendientes en caso de contraer matrimonio contra la voluntad real, este es otro de los principios que parecen haber quedado algo anticuados en nuestros días puesto que van contra todo principio de libertad de la persona ( $\mathrm{y}$ en España no se ha aplicado en los últimos matrimonios morganáticos de la Casa Real). El Rey puede decidir incluso en última instancia con quien ha de casarse el futuro heredero o de lo contrario poder retirarle la corona. 
- Incluso en los países de una mayor tradición Monárquica, como es el caso de Gran Bretaña, los niveles de popularidad de la Monarquía han descendido peligrosamente y esto no se debe, por lo menos totalmente, a determinados escándalos que se encuadran dentro de la vida personal de los miembros reales, sino más bien a determinados aspectos que han quedado algo anticuados en la época actual. Esto también puede deberse a que la Casa real británica no cuida tanto como la española su imagen pública (en los medios de comunicación), algo que en España sí se produce y que hay que analizarlo desde la perspectiva que nuestra Monarquía tiene menos tradición actualmente (hemos tenido un lapsus desde 1931 al 1975 por diversas razones) y nuestra historia está salpicada de mayores cambios políticos que en Gran Bretaña en lo referente a la Jefatura del estado.

\section{Bibliografía}

BURNS MARAÑÓN, Tom (2007): La Monarquía necesaria. Pasado, presente y futuro de la Corona en España. Planeta. Barcelona.

CALDEVILLA DOMíNGUEZ, David: Campaña de imagen sobre la Monarquía española. Madrid. Vision Net. 2004.

CONSTITUCIÓN ESPAÑOLA: Disponible en: www.hylandmadrid.com/libros/es/Constitucion/constitucion_esp.pdf

CACHO, Jesús (2000): El negocio de la libertad. Akal. Madrid.

REVISTA LE MONDE DIPLOMATIQUE EN ESPAÑOL: Disponible en: www.monde-diplomatique.es/

ROMERO BONIFAZ, Carlos (2007): Constituciones comparada y comentadas. Oxfam. Londres. 
SUÁREZ FERNÁNDEZ, LUIS (2003): Nobleza y Monarquía: entendimiento y rivalidad. El proceso de la construcción de la corona española. La esfera de los libros. Madrid.

Páginas Web:

www.udechile.cl/magisterencienciaspoliticas

www.puc.cl/magisterencienciaspoliticas

$\underline{\text { www.ugeorgenton.com/magisterencienciaspoliticas }}$ 